\title{
Nicotinic activation of reticulospinal cells involved in the control of swimming in lampreys
}

\author{
by \\ Didier Le Ray ${ }^{2 \star}$, Frédéric Brocard ${ }^{2}$, Céline Bourcier-Lucas ${ }^{2 \dagger}$, François \\ Auclair $^{2}$, Philippe Lafaille ${ }^{2}$, and Réjean Dubuc ${ }^{1,2}$ \\ ${ }^{1}$ Département de kinanthropologie, Université du Québec à Montréal, H3C 3P8 \\ ${ }^{2}$ Centre de Recherche en Sciences Neurologiques, Université de Montréal, Montréal \\ Québec, Canada, H3C 3J7 \\ * Present address: Laboratoire de Neurobiologie des Réseaux, CNRS-UMR5816, 33405 \\ Talence, France \\ † Performed all anatomical studies
}

Abbreviated title: Nicotinic inputs to reticulospinal cells

Number of text pages (31), figures (10), and tables (0)

Number of words in abstract (215/250), introduction, (476/500), and whole paper (9 165)

${ }^{1}$ To whom correspondence should be addressed:

Dr Réjean Dubuc

Université du Québec à Montréal,

Département de Kinanthropologie,

C.P. 8888, Succ. Centre-ville,

Montréal (Québec), Canada H3C 3P8

Tel: (514) 3435729 Fax: (514) 3436611

Email: dubuc.rejean@uqam.ca

Key words: Brainstem; Acetylcholine; Nicotine; Locomotor control; MLR 


\begin{abstract}
In lampreys as in other vertebrates, brainstem centers play a key role in the initiation and control of locomotion. One such center, the mesencephalic locomotor region (MLR), was identified physiologically at the mesopontine border. Descending inputs from the MLR are relayed by reticulospinal neurons in the pons and medulla, but the mechanisms by which this is done remain unknown. Because previous studies in higher vertebrates and lampreys described cholinergic cells within the MLR region, we investigated the putative role of cholinergic agonists in the MLR-controlled locomotion. The local application of either acetylcholine or nicotine exerted a direct dose-dependent excitation on reticulospinal neurons as well as induced active or fictive locomotion. It also accelerated ongoing fictive locomotion. Choline acetyltransferase-immunoreactive cells were found in the region identified as the MLR of lampreys and nicotinic antagonists depressed, whereas physostigmine enhanced the compound EPSP evoked in reticulospinal neurons by electrical stimulation of this region. In addition, cholinergic inputs from the MLR to reticulospinal neurons were found to be monosynaptic. When the brainstem was perfused with D-tubocurarine, the induction of swimming by MLR stimulation was depressed, but not prevented, in a semi-intact preparation. Altogether, the results support the hypothesis that cholinergic inputs from the MLR to reticulospinal cells play a substantial role in the initiation and the control of locomotion.
\end{abstract}




\section{INTRODUCTION}

Locomotor behaviors include both sensory-evoked locomotion organized at the rhombencephalic level and goal-directed locomotion that requires higher brain structures (Grillner, 1985; McClellan, 1986). The neural elements responsible for these locomotor behaviors are not fully identified, nor are the underlying cellular mechanisms involved. In both cases, however, the supraspinal locomotor command is likely to be channeled via the reticulospinal (RS) system, which constitutes the main descending system involved in the initiation and control of locomotion in lampreys (Brodin et al., 1988; Ohta and Grillner, 1989). Reticulospinal neurons directly activate spinal locomotor networks (Rovainen, 1974; Buchanan and Cohen, 1982) and receive sensory information from various sources (Rovainen, 1982; Bussières \& Dubuc, 1992; Dubuc et al., 1993a,b; Viana Di Prisco et al., 1995; Deliagina et al., 1995), as well as feedback from the spinal locomotor networks (Dubuc \& Grillner, 1989). Cells with such input/output characteristics have been referred to as "command neurons" (see Frost \& Katz, 1996), and this role has been proposed for lamprey RS neurons (McClellan \& Grillner, 1984; McClellan, 1987, 1988).

Recently, we described a cellular mechanism by which cutaneous inputs are transformed into an escape locomotor command through intrinsic properties of RS neurons in lampreys (Viana Di Prisco et al., 1997, 2000). Moreover, we established that brainstem regions rostral to the rhombencephalon are not essential for escape locomotion (Cardin et al., 1999). Goal-directed locomotion on the other hand, has only recently attracted significant interest in lampreys (see El Manira et al., 1997), although exploratory, food seeking, and attack behaviors are all important for the survival of these animals. We have recently shown that lamprey RS cells are controlled by a brainstem structure comparable to the mesencephalic locomotor region (MLR; Sirota et al. 2000) originally described in mammals (for reviews see: Shik \& Orlovsky, 1976; Jordan, 1998). Little is known about the mechanisms by which the MLR acts onto RS neurons to generate locomotion. The pedunculopontine nucleus (PPN), traditionally associated to the physiologically defined MLR (for reviews see: Garcia-Rill \& Skinner, 1986; Jordan, 1998), contains cholinergic neurons that project to the reticular formation of cats and rats 
(Mesulam et al., 1983; Garcia-Rill \& Skinner, 1987a; Skinner et al., 1990; Lai et al., 1999). Interestingly in mammals and birds, the focal injection of acetylcholine agonists within the reticular formation elicits locomotion (Garcia-Rill \& Skinner, 1987a; Sholomenko et al., 1991). Moreover, cholinergic cells were recently seen in the isthmic region of lampreys (Pombal et al., 2001). However, no direct link between a cholinergic command originating from the MLR and locomotion was ever reported in any vertebrate species.

We investigated in lampreys, the effects of cholinergic agonists on RS neurons and on locomotor behavior. Here, we describe that acetylcholine induces a nicotinic receptormediated depolarization of RS cells and elicits locomotion. We also provide evidence supporting our hypothesis that cholinergic inputs play a substantial role in the MLR command to RS cells in lampreys. 


\section{MATERIALS AND METHODS}

\section{Animal preparation}

Experiments were performed on larval $(n=59)$ and adult $(n=28$ newly transformed, and 3 spawning) lampreys, Petromyzon marinus. All procedures conformed to the Canadian Medical Research Council guidelines and were approved by the University Committee for Animal Care and Use. Under tricaine methanesulphonate (MS 222, $100 \mathrm{mg} / \mathrm{l}$; Sigma-Aldrich, Oakville, ON) anesthesia, the animals were opened along the ventral midline and eviscerated. The dissection and experiments were performed in cold oxygenated Ringer's $\left(9^{\circ} \mathrm{C}, \mathrm{pH} 7.4\right)$ with the following composition (in $\mathrm{mM}$ ):, $2.1 \mathrm{KCl}$, 2.6 $\mathrm{CaCl}_{2}, 1.8 \mathrm{MgCl}_{2}, 4$ Hepes, 4 Dextrose, $1 \mathrm{NaHCO}_{3}$. Some experiments were performed in saline with higher divalent cation concentrations, the sodium chloride concentration reduced accordingly (in $\mathrm{mM}$ ): $10.8 \mathrm{CaCl}_{2}, 7.2 \mathrm{MgCl}_{2}$, and $103 \mathrm{NaCl}$. The rostral end of the body was dissected up to the last gill, and the brain and spinal cord were isolated in vitro with the underlying cranium and notochord kept for support. The spinal cord was cut either at the first spinal segment out of 100 or between segmental levels 10 and 20. The responses to the local application of cholinergic agonists were similar in either case.

A semi-intact preparation $(n=42)$ was also used, where the rostral end of the animal was dissected out as described above and pinned down to the Sylgard bottom of the experimental chamber perfused with Ringer's. The caudal two thirds of the body and the tail were left intact to swim freely behind, and insulated bipolar EMG electrodes were inserted into the myotomes with an inter-electrode distance of $3 \mathrm{~mm}$ (Teflon coated stainless steel wire, diameter $50 \mu \mathrm{m}$; California Fine Wire Company, Grover Beach, CA). Two pairs of EMG electrodes were usually placed between segmental levels 20 and 25, one on each side of the body. For decerebration purposes, a complete transection was made between the mesencephalon and the diencephalon. However, in experiments where locomotion was initiated by local application of a cholinergic agonist, the transection was usually performed lower, between the mesencephalon and the rhombencephalon. The local application of cholinergic agonists provided similar results whether the mesencephalon was kept or not. 


\section{Electrophysiology and drug application}

The MLR of semi-intact lampreys was electrically stimulated (1-10 $\mu \mathrm{A}, 1 \mathrm{~ms}$, 5-10 Hz) with glass-coated tungsten electrodes (5 M $\Omega$ with $10 \mu \mathrm{m}$ tip exposure) using a pulse generator S88 (Grass Instrument Co, Quincy, MA) connected to a stimulus isolation unit (Grass Instrument Co). For later histological identification, an electrolytic lesion $(n=12)$ was made at the stimulation site using positive DC current $(5 \mu \mathrm{A})$ applied for $10 \mathrm{~s}$ at the end of experiments.

Reticulospinal neurons in the middle (MRRN, $n=113$ ) and posterior (PRRN, n=5) rhombencephalic reticular nuclei were impaled under visual guidance with sharp glass micropipettes (4M K-acetate, $\sim 100 \mathrm{M} \Omega$ ). In all experiments, the impaled neurons were the largest reticular neurons described by Müller (see Rovainen, 1982) in the brainstem of the lamprey, and only cells with a resting membrane potential consistent throughout the experiment were considered in this study. The intracellular signals were recorded using an Axoclamp 2A (Axon Instruments Inc., Foster City, CA) and directed to a computer via a TL-1 DMA interface (Axon Instruments Inc., sampling rate: 1-5 kHz). Suction electrodes were used to monitor the activity of ventral roots on each side between segmental levels 10 and 20. Acquisition and analysis of RS neuron responses (i.e., peak amplitudes, areas, 10-90\% slopes) were performed using the pClamp9 pack program (Axon Instruments, Inc.).

Small doses (0.4-10.6 $\mathrm{nL})$ of either acetylcholine (1-5 mM) or nicotine (1-5 mM) were pressure-applied locally onto RS neurons through a glass micropipette using a Picospritzer (General Valve Corporation, Fairfield, NJ). Dose-response curves were built by randomly applying short-duration ejections of the drugs with a minimal time interval of 1 min: the random application was used to prevent possible cumulative effects, and the 1 min interval was tested by repeating three times the ejection of the same drug quantity as the minimal delay required to avoid any possible desensitization of the receptors. Fast Green was added in the pipette to monitor the extent of the drug diffusion. When only Fast Green and Ringer's were ejected onto RS cells, no cellular responses were ever observed. To elicit locomotion, larger volumes (30-50 nL) of either cholinergic agonist solutions were ejected over the entire MRRN on both sides. A higher concentration of the cholinergic agonists $(5 \mathrm{mM})$ was sometimes used because the ejected 
solution tended to diffuse in the bathing Ringer's before reaching the RS cells. All other drugs were dissolved in fresh Ringer's and bath applied. These included: 6-cyano-7nitroquinoxaline-2,3-dione (CNQX, $10 \mu \mathrm{M})$, 2-amino-5-phosphonopentanoate (AP-5, $100 \mu \mathrm{M})$, dizocilpine (MK-801, $100 \mu \mathrm{M})$, atropine $(10 \mu \mathrm{M})$, physostigmine (eserine, $100 \mu \mathrm{M})$, D-tubocurarine $(30-100 \mu \mathrm{M}), \alpha$-bungarotoxin $(0.1 \mu \mathrm{M})$, tetrodotoxin (TTX, $3 \mu \mathrm{M})$ and N-methyl-D-aspartate (NMDA, $100 \mu \mathrm{M})$. In such experiments, a Vaseline wall was built just below the rhombencephalon delimiting two distinct, watertight perfusion compartments. NMDA was applied in the spinal cord bath, whereas all other drugs were applied into the brainstem bath. After each bath application of a drug, a wash out period of 15 minutes to more than one hour depending on the drug ejected, was allowed for recovery. All drugs were purchased from Sigma-Aldrich.

\section{Statistical analyses}

Results are expressed as means \pm standard errors. The correlation between the duration of drug ejection and the size of the induced responses was examined with regression analysis. In all cases, linear regressions fitted best the data. The statistical significance for differences between means was established with either a paired Student's t-test (comparisons of 2 groups) or an ANOVA test (comparisons of more than 2 groups). All statistical analyses were carried out using Origin software (OriginLab Corporation, Northampton, MA).

\section{Anatomical studies}

Procedures: Immunohistochemistry for choline acetyltransferase (ChAT), the last enzyme in the synthesis of acetylcholine, was used to study in details the distribution of cholinergic neurons in the isthmic region of adult lampreys Petromyzon marinus $(\mathrm{n}=26)$. The brains were fixed by immersion in $4 \%$ paraformaldehyde in $0.1 \mathrm{M}$ phosphate buffer ( $\mathrm{pH} 7.4)$ overnight. After agarose embedding, transverse sections were cut at $50 \mu \mathrm{m}$ thickness on a vibratome (TPI, St Louis, MO) and collected in $0.1 \mathrm{M}$ phosphate buffer (PB). Free-floating sections were treated with $1 \% \mathrm{H}_{2} \mathrm{O}_{2}$ in phosphate buffered saline (PBS) for 30 minutes to reduce endogenous peroxidase activity. After rinsing in $0.1 \mathrm{M}$ PBS, the presence of ChAT was revealed according to a procedure adapted from Marin et al. (1997), replacing the peroxidase-antiperoxidase technique by the avidin-biotin one. 
Briefly, sections were incubated with the following solutions: $i$ )- Purified goat anti-ChAT serum (Chemicon, Temecula, CA) diluted 1:100 in 0.1 M PBS with 0.5\% Triton X-100, $15 \%$ normal horse serum (Gibco, Burlington, $\mathrm{ON}$ ) and $2 \%$ bovine serum albumin (Vector, Burlingame, CA) for 40 hours at $4{ }^{\circ} \mathrm{C}$; ii)- 0.1 M PBS (3 x 10 minutes); iii)Biotinylated horse anti-goat serum (Vector) diluted 1:50 in the same buffer for 1 hour at room temperature; iv)- $0.1 \mathrm{M}$ PBS (3 x 10 minutes); v)-Avidin-horseradish peroxidase reagent (Vectastain, Elite ABC KIT, Vector) diluted as directed by the manufacturer in PBS for 1 hour at room temperature in darkness; vi)- $0.1 \mathrm{M}$ PBS (3 x 10 minutes). Finally, immunostaining was visualized with the glucose oxidase method of Shu et al. (1988). However, in order to achieve a better control on the duration of reaction, all the reagent concentrations were halved with respect to the initial procedure described by these authors. As a control, the primary antiserum was omitted from a series of sections in each experiment, and this resulted in no specific labeling of somata or fibers.

In some experiments, immunohistochemistry for ChAT was performed on brainstems where an electrolytic lesion had previously been made in the MLR at the end of electrophysiological experiments $(n=12)$. The fixed brains were frozen and cut at $20 \mu \mathrm{m}$ thickness on a cryostat (American Optical, Buffalo, NY), and the sections were mounted on gelatinized slides and left to dry overnight. Immunocytochemistry for ChAT was then performed as described above, but on the mounted sections.

Analysis: Counts and cell size measurements of labeled neurons were made from transverse sections on one side of the brainstem in the rostral rhombencephalon and the mesencephalic tegmentum. All ChAT-immunoreactive cells were counted each time they disappeared as the focus was changed using an optical dissector method (West et al., 1991; see also Coggeshall \& Lekan, 1996). In one specimen, the soma diameter was measured along the longest axis as seen on transverse sections. Photomicrographs were acquired with a digital camera (Coolpix 995, Nikon, Japan) custom-fitted on a microscope (Optiphot-2, Nikon). All the figures were designed using CorelDraw 9 software (Corel Corp., Ottawa, ON) and 3-dimensional reconstructions of the distribution of ChAT- immunoreactive neurons were made using the Autocad 12 software (Autodesk Inc., Montreal, QC). 


\section{RESULTS}

\section{Cholinergic responses in $R S$ neurons}

The local application of acetylcholine $(1 \mathrm{mM})$ onto RS neurons elicited depolarizing responses, the amplitude of which increased linearly with the duration of the drug ejection, until spiking threshold was reached ( $\mathrm{n}=34$; Fig. 1A1). The responses, although reduced, persisted under bath application of $3 \mu \mathrm{M}$ TTX $(n=3)$, indicating that acetylcholine exerted direct excitation of RS neurons. There was a linear increase in the responses as the ejection duration increased (Fig. 1B1). The response area, which takes into account both the amplitude and the duration of the response, displayed a strong positive correlation with the duration of the ejection in normal saline $(r=0.97 ; p<0.001$; Fig. 1A2) as well as under TTX bath perfusion ( $\mathrm{r}=0.97$; $\mathrm{p}<0.001$; Fig. 1B2). With a higher concentration $(5 \mathrm{mM})$ of acetylcholine in the ejection pipette, a focalized ejection onto a given RS neuron generally produced a complete desensitization of the depolarizing response, whereby a second ejection was ineffective, and several minutes were required for recovery ( $\mathrm{n}=5$; not shown). Most of the RS neurons tested responded similarly to the local ejection of acetylcholine.

The bath perfusion of the nicotinic antagonist D-tubocurarine completely blocked the depolarizing response to acetylcholine ( $\mathrm{n}=3$; Fig. $1 C 1$ ), suggesting that the latter resulted exclusively from the activation of nicotinic receptors. In contrast, bathapplication of either atropine ( $\mathrm{n}=5$; Fig. 1C2), or a combination of both NMDA and nonNMDA glutamatergic antagonists, AP5 $(n=4)$ or MK-801 $(n=3)$ and CNQX ( $n=7)$ respectively (not shown), did not alter the subthreshold response of RS neurons to acetylcholine. This indicated that the small amplitude depolarizations induced by acetylcholine, in the absence of any network influences, were mediated exclusively by nicotinic receptors.

Properties of the nicotinic responses

When nicotine (1-2 mM) was substituted for acetylcholine in the ejection pipette, RS neurons from either the MRRN or the PRRN displayed dose-dependent depolarizations similar to those elicited by acetylcholine (n=14; Fig. 2A). Short-duration 
ejection evoked a small depolarization, and the area of the responses increased with the duration of the ejection. The best fit of this relation was obtained with a linear regression $(\mathrm{r}=0.97, \mathrm{p}<0.001$; Fig. $2 B)$. Similarly to acetylcholine, nicotine induced depolarizing responses, the largest of which reached spiking threshold (Fig. 2A). Here again, repeated local applications of a high concentration $(5 \mathrm{mM})$ of nicotine induced a complete desensitization of the response, requiring several minutes for recovery ( $n=3$; not shown). In contrast, repeated pressure-applications of a low concentration $(1 \mathrm{mM})$ of nicotine unmasked interesting properties of the RS neuron responses: when a subsequent nicotine ejection was performed before the membrane potential had returned to its resting value, summation occurred in all of the tested RS cells (Fig. $2 C ; \mathrm{n}=5$ ). The membrane potential of the RS neurons depolarized until spiking threshold was reached and sustained firing of action potentials occurred. Thereafter, additional applications of nicotine did not depolarize the cell membrane further. The temporal summation of responses may be an important factor in the recruitment of RS cell activity by the MLR (see below).

\section{Initiation of swimming by cholinergic agonists}

Because acetylcholine and nicotine evoked sustained firing in the RS neurons of both MRRN and PRRN, we investigated the possibility that the drugs could also induce swimming in a semi-intact preparation $(\mathrm{n}=17)$. Repeated pressure applications of acetylcholine ( 1 or $5 \mathrm{mM}$ ) into the 4th ventricle over most of the MRRN on both sides evoked a long-lasting depolarization in RS neurons accompanied by an increase in EMG activity recorded bilaterally from the body and followed by the onset of swimming (Fig. 3A). Swimming (EMG bursts) developed after spiking occurred in the recorded RS cell and lasted for as long as the cell remained depolarized. The quality of swimming was variable from one experiment to another, and the excitability of the preparation appeared to be critical. Indeed, about half of the acetylcholine applications resulted in only a tonic increase in EMG activity on both sides (not shown). We found no clear relation between the occurrence of this tonic activity and the state of the preparation, suggesting that some yet unknown and uncontrolled factors intrinsic to the RS system might be involved. In contrast, in the other half of the trials, swimming that could last for several minutes was elicited and displayed alternate activity in the right and left side EMGs (Fig. 3B, 3C). The body movements were then comparable to those occurring in intact animals with a wave 
of lateral displacement propagating smoothly from the rostral part of the body to the tail region (not illustrated). Similar results were obtained when nicotine was substituted for acetylcholine in the ejection pipette ( $n=4$; not shown), or when either drugs were ejected over RS cells in the PRRN ( $n=2$; not shown).

\section{Cholinergic control of the swimming activity}

Similar experiments were carried out in the in vitro isolated brainstem-spinal cord preparation where acetylcholine ( 1 or $5 \mathrm{mM}$ ) was locally applied onto the whole MRRN in the absence of prior locomotor activity $(n=12)$. Fictive locomotion that could last for several minutes (Fig. 4A) was then elicited and ventral root discharges alternated on both sides (Fig. 4B). Nicotine ( $1 \mathrm{mM}$; $\mathrm{n}=6)$, ejected either on the MRRN or on the PRRN under the same conditions, also triggered fictive locomotion (not shown).

To study the effects of cholinergic agonists on ongoing fictive locomotion, a double bath paradigm was used where the spinal cord was perfused with Ringer's containing $100 \mu \mathrm{M}$ NMDA to activate the spinal locomotor networks, whereas the brainstem was perfused with normal Ringer's (Fig. 5A). In these experiments $(n=9)$, the ventral root discharges (Fig. 5B left part) initially showed an unstable rhythmic activity immediately after adding NMDA to the spinal bath. This progressively evolved into a fast and stable locomotor rhythm, some 7-10 min later (diamonds in Fig. 5C). The effects of a single local ejection of acetylcholine $(1$ or $5 \mathrm{mM})$ onto the whole MRRN $(n=12)$ differed whether studied on the early unstable or the later stable fictive locomotor rhythm. When ejected early after the NMDA application, acetylcholine produced, with a delay of $30-60 \mathrm{~s}$, a significant increase in the frequency of the ventral root bursts. This is illustrated in figure $5 B$ where there is a $86.7 \pm 0.6 \%$ (mean over 8 experiments: $38.4 \pm 8.7 \%$ ) reduction in period and a $89.1 \pm 0.6 \%$ (mean: $38.6 \pm 9.9 \%$ ) reduction in burst duration. Cumulative data from 12 experiments (Fig. 5C) indicate that acetylcholine consistently speeded up the early locomotor rhythm as compared to when NMDA was applied alone to the spinal cord bath (compare squares with diamonds in Fig. 5C). The inset shows the early part of the graph with an expanded time base. Figure $5 D$ shows that the cycle duration for the first 30 cycles after application of acetylcholine (black bars) was significantly shorter $(\mathrm{p}<0.001)$ than under control conditions (gray bars). The reduction was less pronounced for the following 30 cycles, with no significant difference 
afterwards. In contrast, when the fictive locomotor rhythm had already stabilized after NMDA perfusion $(n=7)$, pressure-ejection of acetylcholine onto RS cells did not elicit any changes in the period nor the burst duration (empty bars in Fig. 5D). This was also true for the five experiments in which acetylcholine was ejected after a previous ejection of the drug had already accelerated the fictive locomotor rhythm (included in the empty bars of Fig. 5D).

\section{ChAT-immunoreactive neurons}

The results described above suggest that acetylcholine receptors are present on lamprey RS neurons and that their activation elicits locomotion. In order to locate the brainstem cholinergic cells that may possibly innervate RS cells, immunohistochemistry directed against ChAT was used $(n=26)$. Amongst the brainstem populations of ChATimmunoreactive neurons, which included also various groups of motoneurons (see also Pombal et al., 2001), two distinct groups of ChAT-immunoreactive neurons were observed in the tegmentum at the mesopontine border, in an area that included the isthmus and the caudal mesencephalon. The first group was located at the rostrocaudal level of the trochlear nucleus, and ChAT-immunoreactive cells were clustered medially in the periaqueductal gray (Fig. 6A, B). Cell counts varied from 545 to 781 with a median of $628(n=6)$. Some of these strongly ChAT-immunoreactive cells were in close proximity with the conspicuous isthmic Müller cell I1 (nomenclature of Rovainen, 1982) in the anterior rhombencephalic reticular nucleus (Fig. 6B). Another group of ChATimmunoreactive cells, i.e. rostral and lateral to the trochlear nucleus, consisted of small ovoid cells that were sparsely distributed in the tegmentum (Fig. 6C,D). Cell counts ranged from 253 to 403 with a median of $352(n=5)$. The cells were significantly less numerous than in the caudal group $(\mathrm{p}<0.01)$. The mean size of cell body in the rostral group of ChAT-reactive neurons $(10.7 \pm 0.2 \mu \mathrm{m})$ was also significantly smaller $(\mathrm{p}<0.01)$ than in the caudal group $(11.8 \pm 0.2 \mu \mathrm{m})$. A $3-\mathrm{D}$ representation illustrating the location of ChAT-immunoreactive neurons within this area of the brainstem (Fig. 7) revealed how the caudal group of ChAT-immunoreactive neurons (Yellow spheres) tightly surrounded the isthmic Müller cell I1 (Green sphere; Fig. 7B,C). More rostrally, the cells from this group tended to be less compact and were more ventral. There was then a transition 
between this group of cells and the rostro-lateral group of ChAT-labeled neurons (Red spheres), which occupied a more dorsal location further rostrally (Fig. 7C).

Effects of nicotinic antagonists on the RS neuron response to MLR electrical stimulation

The electrophysiological observations above indicated a role of acetylcholine in the initiation and the control of locomotion in lampreys. The immunohistochemical experiments confirmed the presence of cholinergic cells at the mesopontine border in the lamprey MLR defined by Sirota et al. (2000). We investigated whether these cells could be a source of cholinergic input to rhombencephalic RS neurons by performing electrical stimulation of the MLR and recording intracellularly from RS neurons. The neurotransmitters involved in the MLR-RS synapses were first investigated: the effects of the nicotinic antagonists D-tubocurarine $(30-100 \mu \mathrm{M})$ or $\alpha$-bungarotoxin $(0.1 \mu \mathrm{M})$ were tested on the EPSPs evoked by single electrical stimulation of the MLR (Fig. 8A1). There was a significant decrease in the EPSP amplitude $(\sim 25 \% ; n=23 ; p<0.001$; Fig. 8A2) and slope ( $23 \% ; \mathrm{n}=23 ; \mathrm{p}<0.05 ;$ not shown). Conversely, a bath application of the acetylcholinesterase inhibitor physostigmine $(100 \mu \mathrm{M})$, which prevents the degradation of acetylcholine in the synaptic cleft, dramatically increased both the amplitude ( $62 \%$; $\mathrm{n}=3 ; \mathrm{p}<0.05)$ and the slope $(\sim 56 \% ; \mathrm{n}=3 ; \mathrm{p}<0.05)$ of the response evoked by single MLR electrical stimulation (Fig. 8B1-2). Because D-tubocurarine did not produce a complete block of the response to MLR stimulation, we investigated the possibility that glutamate might also mediate a part of the MLR input to RS neurons in the lamprey (Fig. 8C). A mixture of NMDA and non-NMDA receptor antagonists $(200 \mu \mathrm{M}$ AP5 and $25 \mu \mathrm{M}$ CNQX, respectively) was bath applied, and the MLR was stimulated electrically. Single EPSPs were dramatically reduced $(\sim 39 \%$; $=2$; $p<0.05$; Fig. $8 C 1)$ but a substantial depolarizing response persisted. This AP5- and CNQX-insensitive component remained constant in high calcium-high magnesium saline and was able to follow a frequency of stimulation of $25 \mathrm{~Hz}$ with no changes in latency and amplitude (Fig. 8C2). This clearly demonstrated that the non-glutamate component was monosynaptic. Interestingly, the addition of D-tubocurarine $(30 \mu \mathrm{M})$ to the glutamate antagonists mixture did not completely suppress the MLR-evoked response, and a small EPSP remained (Fig. 8C1). Although our pharmacological experiments indicated the involvement of various neurotransmitters in the MLR-evoked EPSP in lamprey RS neurons, they nevertheless 
confirmed that cholinergic inputs are present. Furthermore, electrolytic lesions were performed at the stimulation site within the MLR and ChAT-immunohistochemistry was carried out on the brainstem sections (Fig. 9). ChAT-labeled neurons were found around the coagulation site close to the ventricular surface (Fig. 9A,C), corresponding to the more caudal group of cholinergic cells (Fig. 9B).

The implication of the cholinergic component from the MLR to RS neurons was thereafter investigated on locomotor activity in a semi-intact preparation $(n=8)$. The MLR was stimulated at $5 \mathrm{~Hz}$ and EPSPs were evoked in RS cells which displayed a buildup of depolarization until the threshold for spiking was reached and swimming activity followed (Fig. 10Al; see also Sirota et al., 2000). Consistently, after selectively adding the nicotinic antagonist D-tubocurarine $(30-50 \mu \mathrm{M} ; \mathrm{n}=5)$ to the brainstem bath, the membrane potential of RS neurons remained mostly below spiking threshold and swimming did not occur (compare Fig. 10A1 and A2). There was a significant decline of both the peak and the area of the MLR-evoked compound EPSPs ( $<<0.001$; Fig. 10B1-2). The depolarization resulting from the summation of EPSPs induced by repetitive MLR stimulation was decreased (compare traces in control, black, and under D-tubocurarine bath perfusion, gray, in Fig. 10B2; compare also gray circles from control, black circle in Fig. 10B3). Opposite effects were observed when the selective cholinesterase inhibitor physostigmine $(100 \mu \mathrm{M})$ was applied to the brainstem bath: the EPSPs evoked by single electrical stimulation of the MLR were increased in both amplitude and duration ( $<<0.05$, $\mathrm{n}=3$; not shown, but see Fig. $8 B$ for single MLR stimulation), and the depolarization resulting from the $5 \mathrm{~Hz}$ stimulation of the MLR was substantially increased (Fig. 10B3, empty circles) when compared to control (Fig. 10B3, black circle). This resulted in the occurrence of swimming (not shown). It is noteworthy that swimming could still be evoked under D-tubocurarine, but only with higher stimulation intensities (generally, a $30-40 \%$ increase was required; not illustrated). These results indicate that the locomotor input from the MLR to RS cells of lampreys is, at least, partly cholinergic. 


\section{DISCUSSION}

The present study is in accordance with an important role of cholinergic inputs onto rhombencephalic RS neurons in the initiation and control of MLR-evoked locomotion in a vertebrate. Acetylcholine elicited a nicotinic receptor-mediated depolarization in RS cells, accompanied by action potential firing that induced swimming in a semi-intact preparation. In addition, the cholinergic stimulation of RS neurons accelerated ongoing locomotor activity induced pharmacologically by NMDA. Anatomical experiments confirmed the existence of two populations of isthmic cholinergic neurons located in the MLR, the electrical stimulation of which induced locomotion. Furthermore, the perfusion of a nicotinic antagonist dramatically depressed the MLR-evoked locomotor command, preventing the occurrence of swimming at the same stimulation strength.

\section{Cholinergic inputs from the MLR to RS neurons in lamprey}

Two distinct groups of ChAT-immunoreactive cell bodies were present in the mesopontine tegmentum of lampreys, as previously observed by Pombal et al. (2001). The first group consisted of densely clustered cells in the periaqueductal gray, and the second, at a more rostral level, comprised fewer cells that were loosely distributed more laterally within the tegmentum. Comparison with immunohistochemical data from other species (cats: Mitani et al., 1988; rats: Jones, 1990; and amphibians: Marin et al., 1997) suggests that the medially clustered cells corresponds to the laterodorsal tegmental nucleus (LDT), and the more laterally located group of cells to the PPN.

The MLR is a functionally defined brain structure that does not correspond to any single nucleus. Several lines of evidence suggest that cholinergic neurons of the PPN may be part of the MLR in mammals (Garcia-Rill et al., 1983; Garcia-Rill \& Skinner, 1987a; Garcia-Rill et al., 1987; Rye et al., 1987; Coles et al., 1989; Skinner et al., 1990). However, no direct relationship has yet been provided. Here, we demonstrate that the electrical stimulation of the mesopontine region containing cholinergic cells, defined as the MLR of lampreys (Sirota et al., 2000) evokes swimming in a semi-intact preparation, the occurrence of which is depressed by exposing RS neurons to the nicotinic antagonist D-tubocurarine. Moreover, previous studies in mammals indicate that some of the mesopontine cholinergic neurons project to the reticular formation (Garcia-Rill \& 
Skinner, 1987a; Rye et al., 1988). For example, cholinergic neurons of the PPN and the LDT project specifically to the ventromedial medulla in rats (Skinner et al., 1990). In our study, the slope of the responses to MLR stimulation was affected by the nicotinic drugs D-tubocurarine, $\alpha$-bungarotoxin and physostigmine, supporting the hypothesis that the cholinergic input acts directly on RS neurons. Moreover, we found that the non-glutamate component of the MLR-evoked EPSP followed without any changes in amplitude nor delay a $25 \mathrm{~Hz}$ frequency of stimulation. Furthermore, we have previously shown that cells in the MLR region are retrogradely labeled from injections of cobalt-lysine in the rhombencephalic reticular formation (Sirota et al., 2000). Hence, although we cannot exclude the possibility of another synapse intercalated between the MLR and RS cells, altogether our findings strongly support a monosynaptic cholinergic input from the MLR to RS cells in lampreys. Double labeling techniques (retrograde tracing with dextranamines and ChAT immunofluorescence) will thus be useful to confirm a projection from the MLR cholinergic cells to the rhombencephalic reticular formation.

In addition to the cholinergic component of MLR input to RS neurons, pharmacological studies showed the existence of a large glutamatergic component. This raised the possibility that both glutamate and acetylcholine cooperate to the MLR command. Indeed, we did not investigate this hypothesis further, and experiments are now performed to analyze both the source of glutamate (co-release or release by two distinct MLR neuronal populations) and possible cooperative effects of glutamate and acetylcholine.

\section{Cholinergic responses in RS neurons}

In vertebrates, RS neurons respond to cholinergic agonists. Acetylcholine produces either depolarizing, hyperpolarizing, or biphasic responses in RS cells of the cat medial pontine reticular formation, affecting the cell firing frequency in response to glutamate bath perfusion (Greene \& Carpenter, 1981, 1985). Kungel et al. (1994) reported mixed effects of cholinergic agonists onto the discharge pattern of neurons in the caudal pontine reticular nucleus of rats. An injection of atropine within the nucleus reticularis pontis oralis produced a decrease in the rate of discharge in RS cells (Takakusaki et al., 1994). In birds, an injection of carbachol in the ventral division of the central nucleus medulla, an area containing RS cells, induces atropine-sensitive walking, running or flight 
(Sholomenko et al., 1991; Webster \& Steeves, 1988). However, the drug is not effective when injected in the pontine reticular formation. The present study in lamprey RS neurons revealed dose-dependent nicotinic receptor-mediated depolarizations in response to a focal ejection of acetylcholine. These responses persisted under TTX (although reduced), suggesting a direct effect, but possibly associated with some network amplification. Surprisingly, Matthews \& Wickelgren (1979) reported that acetylcholine had no effects on RS cells of the MRRN. However, because the drug was bath-applied in their study, a desensitization of the responses may have occurred as reported here. We also found that the local ejection of either nicotinic agonists did not always elicit consistent responses in RS neurons. In some cases, the local application of a nicotinic agonist evoked no response or only subthreshold depolarizations from the RS neuron (not illustrated). However, this was temporary, and a longer delay or changing the agonist solution was usually sufficient to observe a cholinergic response. It is possible that some receptor desensitization occurs due to uncontrolled spontaneous cholinergic activity. Supporting this hypothesis is the observation that adding the selective cholinesterase inhibitor physostigmine alone was sufficient to unmask spontaneous acetylcholinemediated depolarizations ( $\mathrm{n}=5$; not illustrated).

\section{Acetylcholine and MLR-controlled swimming}

As in mammals (Garcia-Rill \& Skinner, 1987b; Iwakiri et al., 1995), MLR inputs in lampreys are relayed to the spinal cord by the rhombencephalic RS neurons (Sirota et al., 2000). Swimming evoked in response to MLR stimulation generally needs several seconds of repeated stimulation to develop, due to a slow buildup of depolarization in the RS cells; the onset delay of swimming decreases as the intensity or frequency of stimulation increases (Sirota et al., 2000). Here, we report that MLR inputs to RS neurons are partly mediated by acetylcholine, and that nicotinic responses show summation properties. The latter may participate to the slow buildup of depolarization and the delayed swimming onset that occur at low stimulation intensities. According to this assumption, the buildup of the response to a $5 \mathrm{~Hz}$ stimulation of the MLR was dramatically reduced in the presence of a nicotinic antagonist and largely increased in the presence of physostigmine, which resulted in the blockade or the facilitation of the initiation of swimming activity, respectively. In such a view, higher stimulation 
frequencies would result in a faster depolarization in RS cells and a shorter onset delay for swimming. Of course, other neurotransmitters may be involved (see Fig. 8Cl) and increasing the intensity of stimulation reversed the blocking of swimming induced with a nicotinic antagonist, presumably through the activation of other non-cholinergic neurons in the MLR. Nevertheless, our results emphasize an important role of acetylcholine in the initiation of locomotion by MLR stimulation.

The local application of nicotinic agonists onto rhombencephalic RS neurons generally produced an increase of the locomotor output. In the absence of prior activity, nicotinic agonists triggered swimming in a semi-intact preparation. When fictive locomotion was induced by perfusion of NMDA onto the spinal cord, the nicotinic activation of RS neurons accelerated the ongoing locomotor rhythm. This acceleration is likely to result from an increase in the excitatory amino acid drive onto the spinal locomotor networks as RS neurons are excited by acetylcholine. This accelerating effect was nevertheless limited, perhaps due to gating of descending inputs during NMDAinduced swimming or to intrinsic limits of the spinal locomotor networks themselves. It was shown previously that vestibular inputs to RS neurons are depressed by adding NMDA to the Ringer's (Bussières \& Dubuc, 1992; Alford \& Dubuc, 1993). Wannier and collaborators (1998) demonstrated that lamprey RS neurons have differential effects on locomotion, including both excitatory and inhibitory influences. In our hands, nicotinic stimulation of the rhombencephalic RS neurons only induced an acceleration of the locomotor rhythm, suggesting that excitatory RS neurons are the main cholinergic targets.

\section{Functional considerations}

The MLR-evoked locomotor behavior is established on a slow, graded depolarization of the RS neurons (Sirota et al., 2000). The present study indicates that this graded command seems to be mediated, at least in part, by acetylcholine. In contrast, sensory-evoked escape swimming relies on the occurrence of a fast, large and longlasting depolarizing plateau in RS cells in response to a single high intensity stimulus (Viana Di Prisco et al., 1997, 2000). The plateaus require the activation of NMDA receptors. This could result from a different function of either command to RS neurons. The latter produces a fast behavioral response that needs to last long enough (the plateau) 
to guarantee the safety of the animal, such as for example in the case of a predator attack. In contrast, the MLR command generates a locomotor behavior that has to be fully adapted (gradual depolarization) and goal-directed compatible with exploratory and appetitive behaviors, which have been proposed to be channeled through the MLR in mammals (Sinnamon, 1993; for a review see Jordan, 1998).

In this study, we focused on the nicotinic component of the cholinergic inputs to RS cells. Muscarinic effects could also be present, although atropine had no effects on acetylcholine-evoked small amplitude depolarizations of RS neurons. We have recently reported that acetylcholine, through muscarinic receptors, modulates the RS cell responses to glutamate, suggesting a role in the control of locomotion (Le Ray et al., in prep). Similarly, anatomical studies showed that numerous neurons in the MLR remained unstained after ChAT-immunohistochemistry, and the MLR-evoked EPSPs in RS neurons were affected only partly by nicotinic antagonists and partly by glutamate antagonists. Taken together, these results demonstrate that the initiation and the control of locomotion require complex mechanisms and that acetylcholine is not the only neurotransmitter involved in the MLR command in lampreys. Rather, goal-directed locomotion may result from the co-activation (cooperation?) of several excitatory commands originating in the MLR including cholinergic and glutamatergic inputs. Experiments are underway to test this hypothesis. 


\section{ACKNOWLEDGEMENTS}

This work was supported by the Canadian Institutes for Health Research (CIHR) and the Fonds pour la Formation des Chercheurs et l'Aide à la Recherche (FCAR, Québec). D.L.R. was a fellow from the Institut National de la Santé et de la Recherche Médicale (France), the Ministère de l'Éducation du Québec, and the Fondation de l'Université du Québec à Montréal. F.B. was a fellow from the Fondation pour la Recherche Médicale (France) and Jasper Fellowship (Québec). C.B.L. and P.L. received a studentship from FCAR and CIHR grants, respectively. The authors wish to express their gratitude to D. Veilleux for her assistance with the experiments and to Y. Breton for his expertise in producing the 3D representations of cell groups. We thank Mr.W.D. Swink and Mrs. M.K. Jones from the Lake Huron Biological Station as well as Mr. J.E. Gersmehl, E. Howe, and W. Boufard from the U.S. Fish and Wildlife Service for their kind supply of lampreys. 


\begin{tabular}{clll} 
& & \multicolumn{1}{c}{ ABBREVIATIONS } \\
Drugs & & \\
AP-5 & $:$ & 2-amino-5-phosphonopentanoate \\
CNQX & $:$ & 6-cyano-7-nitroquinoxaline-2,3-dione \\
MK-801 & $:$ & Dizocilpine \\
NMDA & $:$ & N-methyl-D-aspartate \\
TTX & $:$ & Tetrodotoxin \\
Others & & \\
ChAT & $:$ & Choline acetyltransferase \\
EMG & $:$ & Electromyograms \\
EPSP & $:$ & Excitatory postsynaptic potential \\
LDT & $:$ & Laterodorsal tegmental nucleus \\
MLR & $:$ & Mesencephalic locomotor region \\
MRRN & $:$ & Middle rhombencephalic reticular nuclei \\
PPN & $:$ & Pedunculopontine nucleus \\
PRRN & $:$ & Posterior rhombencephalic reticular nuclei \\
RS & $:$ & Reticulospinal \\
& &
\end{tabular}




\section{REFERENCES}

Alford, S. \& Dubuc, R. (1993) Glutamate metabotropic receptor mediated depression of synaptic inputs to lamprey reticulospinal neurones. Brain Res., 605, 175-179.

Brodin, L., Grillner, S., Dubuc, R., Ohta, Y., Kasicki, S. \& Hokfelt, T. (1988) Reticulospinal neurons in lamprey: transmitters, synaptic interactions and their role during locomotion. Arch. Ital. Biol., 126, 317-345.

Buchanan, J.T. \& Cohen, A.H. (1982) Activities of identified interneurons, motoneurons, and muscle fibers during fictive swimming in the lamprey and effects of reticulospinal and dorsal cell stimulation. J. Neurophysiol., 47, 948-960.

Bussières, N. \& Dubuc, R. (1992) Phasic modulation of transmission from vestibular inputs to reticulospinal neurons during fictive locomotion in lampreys. Brain Res., 582, 147-153.

Cardin, S., Le Ray, D., Robitaille, R. \& Dubuc, R. (1999) Motor responses elicited by skin stimulation in lampreys. Soc. Neurosci. Abstr., 25(2), p. 1906.

Coggeshall, R.E. \& Lekan, H.A. (1996) Methods for determining numbers of cells and synapses: a case for more uniform standards of review. J. Comp. Neurol., 364, 6-15.

Coles, S.K., Iles, J.F. \& Nicolopoulos-Stournaras, S. (1989) The mesencephalic centre controlling locomotion in the rat. Neuroscience, 28, 149-157.

Deliagina, T., Ullén, F., Gonzalez, M., Ehrsson, H., Orlovsky, G. \& Grillner, S. (1995) Initiation of locomotion by lateral line photoreceptors in lamprey: behavioural and neurophysiological studies. J. Exp. Biol., 198, 2581-2591.

Dubuc, R., Bongianni, F., Ohta, Y. \& Grillner, S. (1993a) Anatomical and physiological study of brainstem nuclei relaying dorsal column inputs in lampreys. J. Comp. Neurol., 327, 260-270.

Dubuc, R., Bongianni, F., Ohta, Y. \& Grillner, S. (1993b) Dorsal root and dorsal column mediated synaptic inputs to reticulospinal neurons in lampreys: involvement of 
glutamatergic, glycinergic, and GABAergic transmission. J. Comp. Neurol., 327, 251-269.

Dubuc, R. \& Grillner, S. (1989) The role of spinal cord inputs in modulating the activity of reticulospinal neurons during fictive locomotion in the lamprey. Brain Res., $\mathbf{4 8 3}$, 196-200.

El Manira, A., Pombal, M.A. \& Grillner, S. (1997) Diencephalic projection to reticulospinal neurons involved in the initiation of locomotion in adult lampreys Lampetra fluviatilis. J. Comp. Neurol., 389, 603-616.

Frost, W.N. \& Katz, P.S. (1996) Single neuron control over a complex motor program. Proc. Natl. Acad. Sci. USA, 93, 422-426.

Garcia-Rill, E., Houser, C.R., Skinner, R.D., Smith, W. \& Woodward, D.J. (1987) Locomotion-inducing sites in the vicinity of the pedunculopontine nucleus. Brain Res. Bull., 18, 731-738.

Garcia-Rill, E., Skinner, R.D. \& Fitzgerald, J.A. (1983) Activity in the mesencephalic locomotor region during locomotion. Exp. Neurol., 82, 609-622.

Garcia-Rill, E. \& Skinner, R.D. (1986) The basal ganglia and the mesencephalic locomotor region. In Grillner, S., Stein, P.S.G., Stuart, D.G., Forssberg, H. \& Herman, R.M. (eds), Neurobiology of vertebrate locomotion. Macmillan Press Ltd, London, pp. 77-103.

Garcia-Rill, E. \& Skinner, R.D. (1987a) The mesencephalic locomotor region. I. Activation of a medullary projection site. Brain Res, 411, 1-12.

Garcia-Rill, E. \& Skinner, R.D. (1987b) The mesencephalic locomotor region. II. Projections to reticulospinal neurons. Brain Res, 411, 13-20.

Greene, R.W. \& Carpenter, D.O. (1981) Biphasic responses to acetylcholine in mammalian reticulospinal neurons. Cell Mol. Neurobiol., 1, 401-405. 
Greene, R.W. \& Carpenter, D.O. (1985) Actions of neurotransmitters on pontine medical reticular formation neurons of the cat. J. Neurophysiol., 54, 520-531.

Grillner, S. (1985) Neurobiological bases of rhythmic motor acts in vertebrates. Science, 228, 143-149.

Iwakiri, H., Oka, T., Takakusaki, K. \& Mori, S. (1995) Stimulus effects of the medial pontine reticular formation and the mesencephalic locomotor region upon medullary reticulospinal neurons in acute decerebrate cats. Neurosci. Res., 23, 47-53.

Jones, B.E. (1990) Immunohistochemical study of choline acetyltransferaseimmunoreactive processes and cells innervating the pontomedullary reticular formation in the rat. J. Comp. Neurol., 295, 485-514.

Jordan, L.M. (1998) Initiation of locomotion in mammals. Ann. NY Acad. Sci., 860, 8393.

Lai, Y.Y., Clements, J.R., Wu, X.Y., Shalita, T., Wu, J.P., Kuo, J.S. \& Siegel, J.M. (1999) Brainstem projections to the ventromedial medulla in cat: retrograde transport horseradish peroxidase and immunohistochemical studies. J. Comp. Neurol., 408, 419-436.

Kungel, M., Ebert, U., Herbert, H. \& Ostwald, J. (1994) Substance P and other putative transmitters modulate the activity of reticular pontine neurons: an electrophysiological and immunohistochemical study. Brain Res., 643, 29-39.

Marin O., Gonzalez A. (1999) Origin of tectal cholinergic projections in amphibians: a combined study of choline acetyltransferase immunohistochemistry and retrograde transport of dextran amines. Vis. Neurosci., 16, 271-283.

Marin, O., Smeets, W.J. \& Gonzalez, A. (1997) Distribution of choline acetyltransferase immunoreactivity in the brain of anuran (Rana perezi, Xenopus laevis) and urodele (Pleurodeles waltl) amphibians. J. Comp. Neurol., 382, 499-534.

Matthews, G. \& Wickelgren, W.O. (1979) Glycine, GABA and synaptic inhibition of reticulospinal neurones of lamprey. J. Physiol. (Lond), 293, 393-415. 
McClellan, A.D. (1986) Command systems for initiating locomotion in fish and amphibians: parallels to initiation systems in mammals. In Grillner, S., Stein, P.S.G., Stuart, D.G., Forssberg, H. \& Herman, R.M. (eds), Neurobiology of vertebrate locomotion. Macmillan Press Ltd, London, pp. 3-20.

McClellan, A.D. (1987) In vitro CNS preparations: unique approaches to the study of command and pattern generation systems in motor control. J. Neurosci. Meth., 21, 251-264.

McClellan, A.D. (1988) Brainstem command systems for locomotion in the lamprey: localization of descending pathways in the spinal cord. Brain Res., 457, 338-349.

McClellan, A.D. \& Grillner, S. (1984) Activation of 'fictive swimming' by electrical microstimulation of brainstem locomotor regions in an in vitro preparation of the lamprey central nervous system. Brain Res., 300, 357-361.

Mesulam, M.M., Mufson, E.J., Wainer, B.H. \& Levey, A.I. (1983) Central cholinergic pathways in the rat: an overview based on an alternative nomenclature (Ch1-Ch6). Neuroscience, 10, 1185-1201.

Mitani, A., Ito, K., Hallanger, A.E., Wainer, B.H., Kataoka, K. \& McCarley, R.W. (1988) Cholinergic projections from the laterodorsal and pedunculopontine tegmental nuclei to the pontine gigantocellular tegmental field in the cat. Brain Res., 451, 397-402.

Ohta, Y. \& Grillner, S. (1989) Monosynaptic excitatory amino acid transmission from the posterior rhombencephalic reticular nucleus to spinal neurons involved in the control of locomotion in lamprey. J. Neurophysiol., 62, 1079-1089.

Pombal, M.A., Marin, O. \& Gonzalez, A. (2001) Distribution of choline acetyltransferase-immunoreactive structures in the lamprey brain. J. Comp. Neurol., 431, 105-126.

Rovainen, C.M. (1974) Synaptic interactions of reticulospinal neurons and nerve cells in the spinal cord of the sea lamprey. J. Comp. Neurol., 154, 207-223. 
Rovainen, C.M. (1982) Neurophysiology. In Hardisty, M.W. \& Potter, I.C. (eds), The Biology of Lampreys, volume 4A. Academic Press, London, pp. 1-136.

Rye, D.B., Saper, C.B., Lee, H.J. \& Wainer, B.H. (1987) Pedunculopontine tegmental nucleus of the rat: cytoarchitecture, cytochemistry, and some extrapyramidal connections of the mesopontine tegmentum. J. Comp. Neurol., 259, 483-528.

Rye, D.B., Lee, H.J., Saper, C.B. \& Wainer, B.H. (1988) Medullary and spinal efferents of the pedunculopontine tegmental nucleus and adjacent mesopontine tegmentum in the rat. J. Comp. Neurol., 269, 315-341.

Shik, M.L. \& Orlovsky, G.N. (1976) Neurophysiology of locomotor automatism. Physiol. Rev., 56, 465-501.

Sholomenko, G.N., Funk, G.D. \& Steeves, J.D. (1991) Avian locomotion activated by brainstem infusion of neurotransmitter agonists and antagonists. I. Acetylcholine, excitatory amino acids and substance P. Exp. Brain Res., 85, 659-673.

Sinnamon, H.M. (1993) Preoptic and hypothalamic neurons and the initiation of locomotion in the anesthetized rat. Prog. Neurobiol., 41, 323-344.

Sirota, M.G., Viana Di Prisco, G. \& Dubuc, R. (2000) Stimulation of the mesencephalic locomotor region elicits controlled swimming in semi-intact lampreys. Eur. J. Neurosci., 12, 4081-4092.

Skinner, R.D., Kinjo, N., Ishikawa, Y., Biedermann, J.A. \& Garcia-Rill, E. (1990) Locomotor projections from the pedunculopontine nucleus to the medioventral medulla. Neuroreport, 1, 207-210.

Shu, S.Y., Ju, G. \& Fan, L.Z. (1988) The glucose oxidase-DAB-nickel method in peroxidase histochemistry of the nervous system. Neurosci. Lett., 85, 169-171.

Takakusaki, K., Shimoda, N., Matsuyama, K. \& Mori, S. (1994) Discharge properties of medullary reticulospinal neurons during postural changes induced by intrapontine injections of carbachol, atropine and serotonin, and their functional linkages to hindlimb motoneurons in cats. Exp. Brain Res., 99, 361-374. 
Viana Di Prisco, G., Ohta, Y., Bongianni, F., Grillner, S. \& Dubuc, R. (1995) Trigeminal inputs to reticulospinal neurones in lampreys are mediated by excitatory and inhibitory amino acids. Brain Res., 695, 76-80.

Viana Di Prisco, G., Pearlstein, E., Robitaille, R. \& Dubuc, R. (1997) Role of sensoryevoked NMDA plateau potentials in the initiation of locomotion. Science, 278, 11221125.

Viana Di Prisco, G., Pearlstein, E., Le Ray, D., Robitaille, R. \& Dubuc, R. (2000) A cellular mechanism for the transformation of a sensory input into a motor command. J. Neurosci., 20, 8169-8176.

Wannier, T., Deliagina; T.G., Orlovsky, G.N. \& Grillner, S. (1998) Differential effects of the reticulospinal system on locomotion in lamprey. J. Neurophysiol., 80, 103-112.

Webster, D.M. \& Steeves, J.D. (1988) Origins of brainstem-spinal projections in the duck and goose. J. Comp. Neurol., 273, 573-583.

West, M.J., Slomianka, L. \& Gundersen, H.J. (1991) Unbiased stereological estimation of the total number of neurons in the subdivisions of the rat hippocampus using the optical fractionator. Anat. Rec., 231, 482-497. 


\section{FIGURE LEGENDS}

Figure 1: Acetylcholine-evoked responses in reticulospinal neurons. A: Local ejections of acetylcholine $(1 \mathrm{mM})$ of increasing duration (50, 100, 150, 200 and $600 \mathrm{~ms}, A C h)$ elicit dose-dependent depolarizations in an intracellularly recorded RS neuron of the MRRN (A1). The relationship between the duration of the acetylcholine ejection and the area of the RS response is linear (A2). B: The perfusion of $3 \mu \mathrm{M}$ tetrodotoxin reduces the response to acetylcholine local ejection, but a fast depolarization persists (B1). The relationship between the duration of acetylcholine ejection and the RS response shows a strong linear correlation (B2). C: The depolarization evoked by a $100 \mathrm{~ms}$ ejection of acetylcholine is suppressed by the superfusion of D-tubocurarine $(30-100 \mu \mathrm{M}, C 1)$ but is unaffected by the superfusion of atropine $(10 \mu \mathrm{M}, C 2)$. Thick lines: control; thin lines: under perfusion of the antagonist.

Figure 2: Nicotine-evoked responses in reticulospinal neurons. A: Local ejections of nicotine $(1 \mathrm{mM})$ of increasing duration $(50,150,250,300$ and $350 \mathrm{~ms}$, Nico) elicit dosedependent depolarizations in an intracellularly recorded RS neuron. $B$ : Linear relationship between the duration of the nicotine ejection and the area of the RS response. $C$ : A single local ejection of nicotine (150 ms; Nico) evokes a transient depolarization in an RS neuron (left). The depolarizations sum up when the ejections are repeated within a short time interval (right). $A$ and $B$ : same cell.

Figure 3: Acetylcholine induced active swimming in a semi-intact preparation. A: Four repeated local ejections $(300 \mathrm{~ms})$ of acetylcholine $(1 \mathrm{mM}, A C h)$ were made onto the MRRN covering the entire nucleus on both sides without spreading to other rhombencephalic reticular nuclei. A slow depolarization with spiking occurs in a MRRN neuron and is followed by swimming ( $r E M G$ and $l E M G$ on the right and the left side, respectively). $B, C$ : The EMG activity can last several minutes (in $B$, trace cut after $30 \mathrm{~s}$ ) and shows clear left and right alternation $(C)$. $C$ shows on a faster time base the traces in the gray area in $B$. 
Figure 4: Acetylcholine induces fictive locomotion. Three repeated local ejections $(300 \mathrm{~ms})$ of acetylcholine $(1 \mathrm{mM}, A C h)$ trigger a fictive locomotor bout in ventral roots on the right and left sides of the spinal cord ( $r V R$ and $l V R$, respectively). Fictive locomotion lasts several minutes $(A)$ and shows clear right and left alternation $(B) . B$ shows on a faster time base the traces in the gray area in $A$.

Figure 5: Acetylcholine accelerates the NMDA-induced locomotor rhythm. $A$ : Experimental design. A Vaseline wall was built to separate the brainstem from the spinal cord allowing the selective perfusion of the latter with NMDA $(100 \mu \mathrm{M})$ to elicit fictive swimming. B: Three local ejections $(200 \mathrm{~ms})$ of $1 \mathrm{mM}$ acetylcholine onto the MRRN accelerate the ongoing rhythm previously induced by selective bath perfusion of the spinal cord with NMDA (trace discontinued during $30 \mathrm{~s}$ ). $C$ : Mean period of NMDAinduced bursts as a function of time with (arrow, black squares) and without (gray diamonds) a local application of acetylcholine $(n=12)$. Inset displays an expanded representation of the first $200 \mathrm{~s}$. $D$ : Changes in burst mean period as a function of the number of cycles of fictive swimming in the absence (gray bars) or in the presence (black bars) of acetylcholine local ejection $(n=12)$. Empty bars include examples where acetylcholine was ejected after the NMDA rhythm had already stabilized (i.e., >90 min after NMDA superfusion on the spinal cord) or after a previous injection of acetylcholine had already been made. Note the absence of change in the cycle duration. $* * *: p<0.001$, $*: \mathrm{p}<0.05$, ns: non significant.

Figure 6: ChAT-immunoreactive neurons at the mesopontine border. A: Photomicrograph from a transverse section showing clustered ChAT-immunoreactive neurons in the caudal group. B: Magnification of the boxed area in $A$ illustrating ChAT-immunoreactive cells surrounding the large isthmic Müller cell (I1) in the anterior rhombencephalic reticular nucleus. $C$ : Photomicrograph from a transverse section showing ChAT-immunoreactive neurons sparsely distributed in the rostral lateral group. $D$ : Magnification of the boxed area in $C$. Scale bars: $200 \mu \mathrm{m}$ in $A$ and $C, 50 \mu \mathrm{m}$ in $B$ and $D$. mlf: medial longitudinal fasciculus; I1: first isthmic Müller cell of the anterior rhombencephalic reticular nucleus; MT: mesencephalic tectum; IV: trochlear nucleus. 
Figure 7: Three-dimensional representation of the position of ChAT-immunoreactive cells in the isthmic region. Each sphere represents a ChAT-immunoreactive neuron. For clarity, the diameter of the spheres was doubled as compared to the true diameter of the cells. A: 3-D reconstruction from 29 transverse sections (20 $\mu \mathrm{m}$-thickness) showing the clustered periventricular group (yellow spheres) surrounding the large isthmic Müller cell I1 (green sphere) and the more lateral and rostral group in the mesencephalic tegmentum (red spheres). The two neuronal populations are shown at high magnification in transverse view $(B)$ and sagittal view $(C)$. Two orthogonal planes were added for a perspective view. In $B$, caudal is toward the observer and in $C$, lateral is toward the observer. Scale bars: $400 \mu \mathrm{m}$ in $A$ and $200 \mu \mathrm{m}$ in $B$ and $C$. V: ventral; R: rostral; C: caudal; L: lateral.

Figure 8: Effects of cholinergic drugs on synaptic responses evoked in RS neurons by single stimuli delivered to the MLR. A1: Depressed MLR-evoked EPSP in RS neurons under D-tubocurarine $(D$-tubo, $30 \mu \mathrm{M})$ perfusion. A2: Histograms of the single EPSP mean peak amplitude and slope in control (filled bars) and under bath perfusion of D-tubocurarine (30-50 $\mu \mathrm{M}$, empty bars). B1: Enhanced MLR-evoked EPSP under physostigmine (Physo, $100 \mu \mathrm{M}$ ) perfusion. B2: Histograms of single EPSP mean peak amplitude and slope in control (filled bars) and under physostigmine bath perfusion (empty bars). C1: MLR-evoked EPSPs are reduced but not completely blocked by CNQX $(25 \mu \mathrm{M})$ and AP5 $(200 \mu \mathrm{M})$. The EPSP component insensitive to glutamate antagonists was further reduced by D-tubocurarine $(30 \mu \mathrm{M})$, but not abolished. $C 2$ : The glutamate antagonists-resistant EPSP followed with a constant latency the MLR high frequency stimulation in a solution of high divalent cations (superposition of 10 consecutive traces). In each condition, mean traces depicted in this figure are averages of three to five responses. $* * *: \mathrm{p}<0.001, *: \mathrm{p}<0.05$.

Figure 9: ChAT-immunoreactive cells in and around the MLR-coagulation site in one larval lamprey. A: Photomicrograph from a transverse section at the isthmic level showing the intact side (on the left) and the caudal part of the coagulation site (on the right). $B$ : Schematic representation from the transverse section showing the location of ChAT-immunoreactive cells and the extent of the coagulation site (gray area) drawn from 
this section and more rostral serial sections. $C$ : Magnification of the boxed area in $B$ showing some of the ChAT-immunoreactive cells in the periaqueductal gray of the intact side. $D$ : Same as in $\mathrm{C}$, but on the side of the coagulation site. Scale bars: $100 \mu \mathrm{m}$ in $A$ and $B, 50 \mu \mathrm{m}$ in $C$ and $D$.

Figure 10: D-tubocurarine effects on MLR-evoked locomotion. A1: Control response elicited by a $5 \mathrm{~Hz}$ stimulation of the MLR (MLR St). The spiking activity induced in the RS neuron by the stimulation of the MLR precedes the onset of swimming characterized by alternate EMG activities on both right and left sides of the body (rEMG and IEMG, respectively). A2: The bath perfusion of D-tubocurarine $(30-50 \mu \mathrm{M})$ dramatically reduces spiking in RS neurons and swimming does not occur, even when the stimulation is maintained for a longer duration. B1: Histograms illustrating the changes in the mean peak and mean area of the compound EPSPs under bath perfusion of D-tubocurarine as compared to control (normalized values). ***: $\mathrm{p}<0.001$. B2: Superimposition of the EPSPs evoked by the $5 \mathrm{~Hz}$ stimulation of the MLR in control (black) and under the bath perfusion of D-tubocurarine (gray). B3: Plot of the relative cell depolarization as a function of the relative mean area of the MLR-evoked EPSP. The depolarization corresponding to a mean area in control (black circle) is centered on 100\%-area and $100 \%$-depolarization. The perfusion of D-tubocurarine (gray circles) reduces both the EPSP area and the depolarization, whereas perfusion of physostigmine (empty circles) increases both the EPSP area and cell depolarization. 
Le Ray et al., 2002

Figure 1
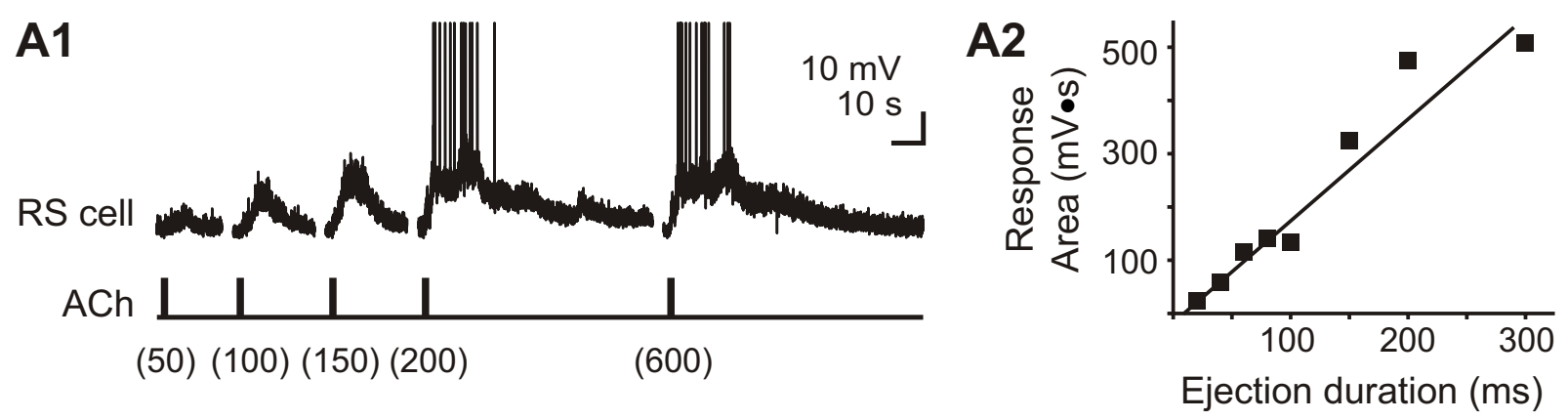

B1

Ejection duration (ms)
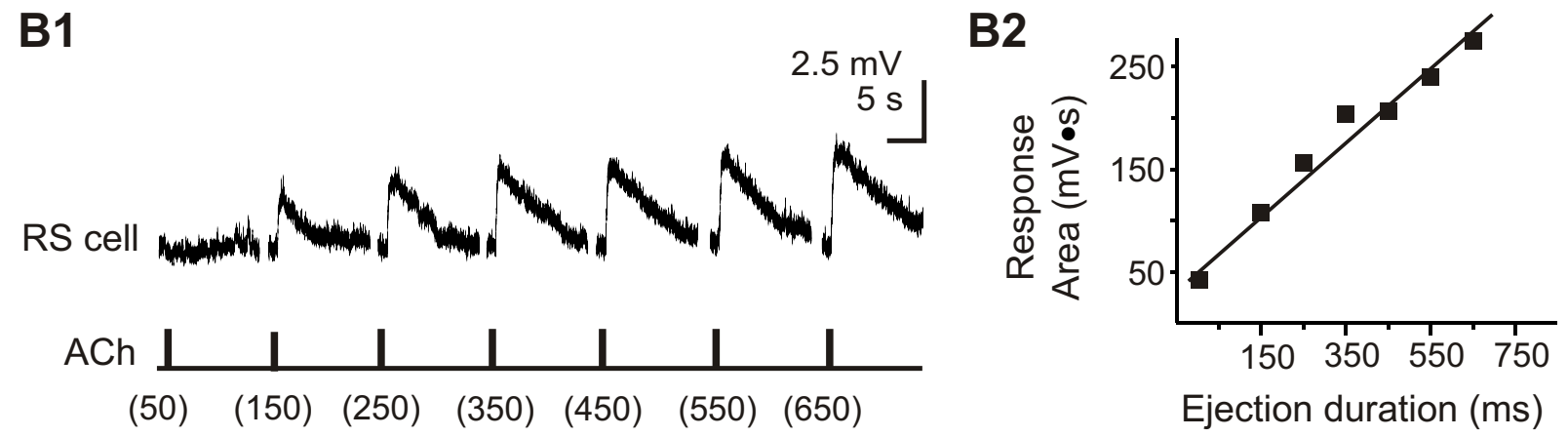

C1

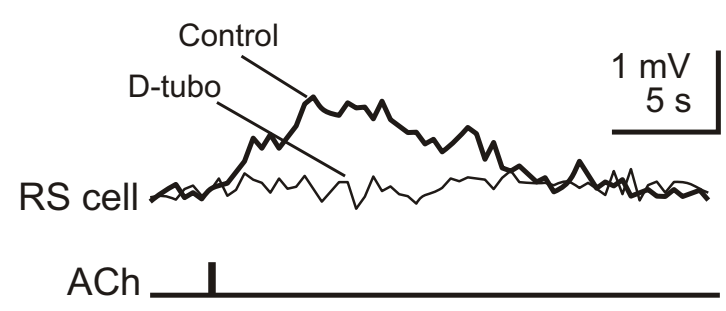

C2

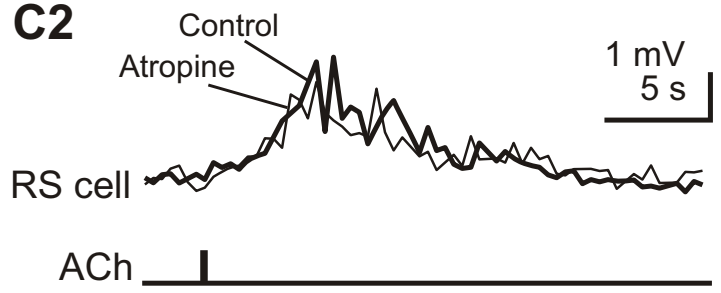




\section{Le Ray et al., 2002}

Figure 2

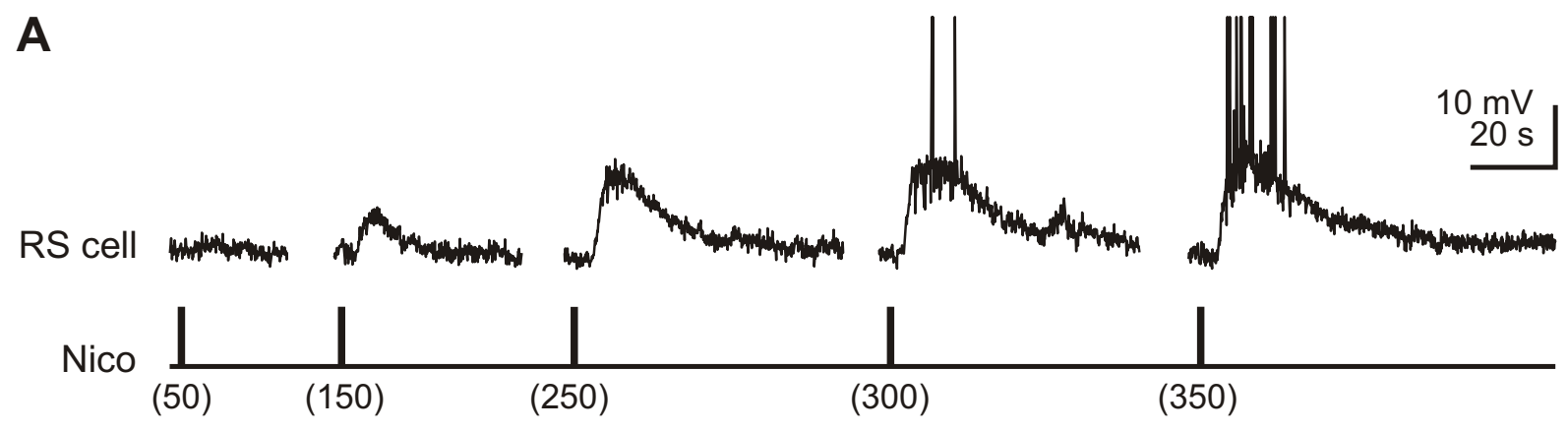

B

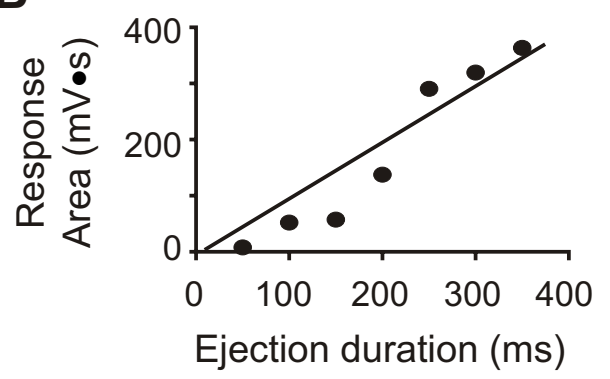

C
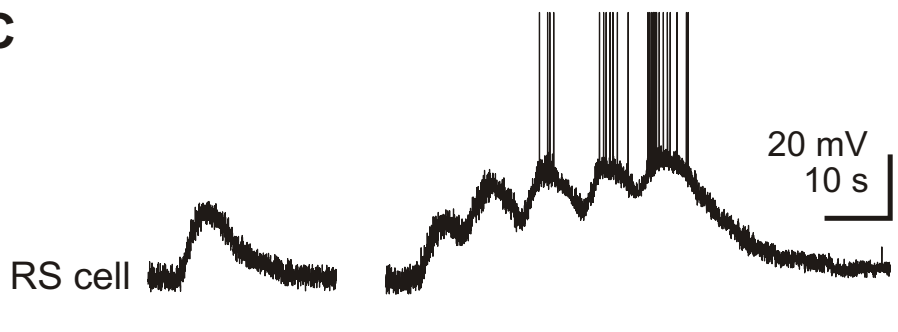
Nico 


\section{Le Ray et al., 2002}

Figure 3

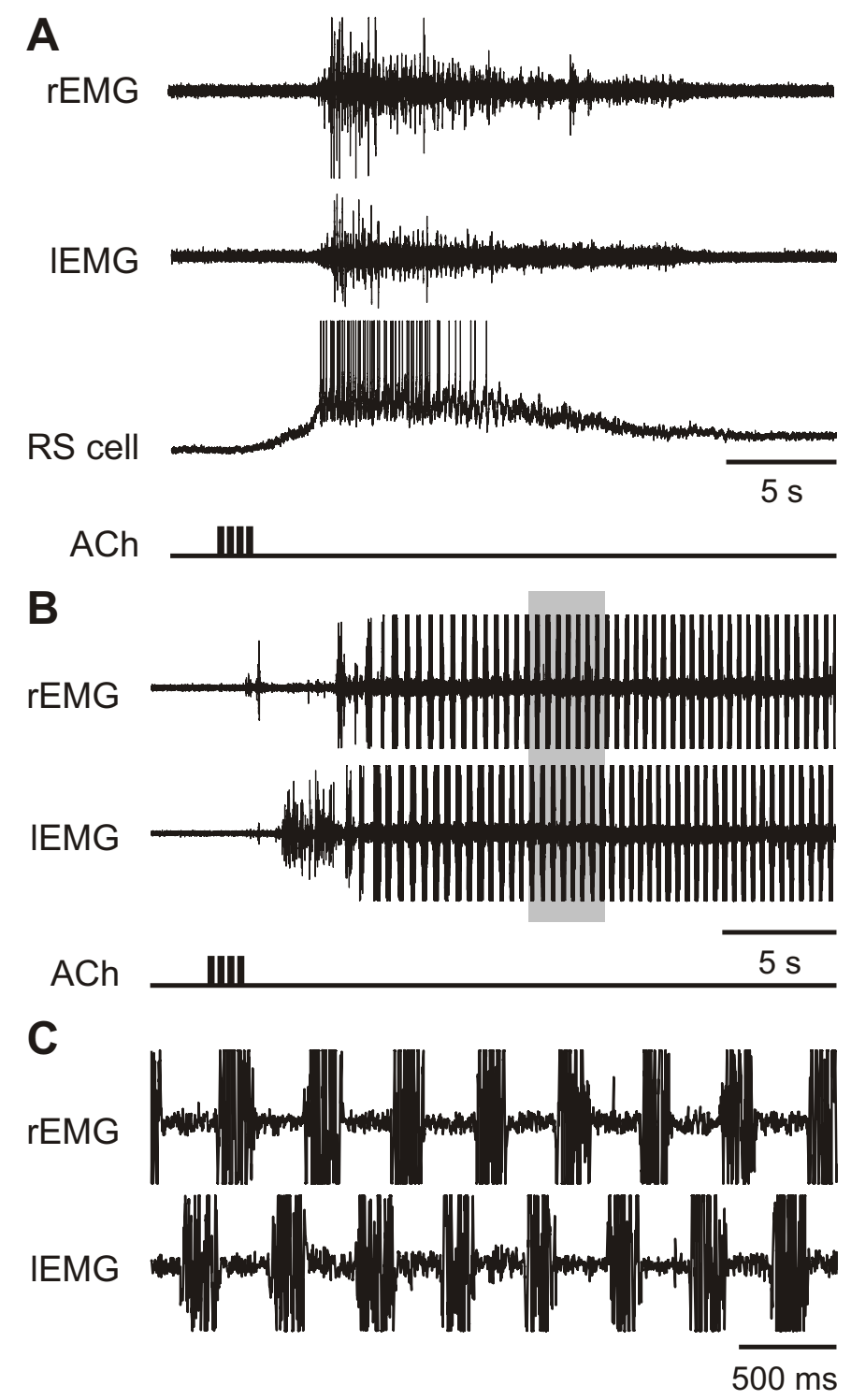




\section{Le Ray et al., 2002}

Figure 4

A

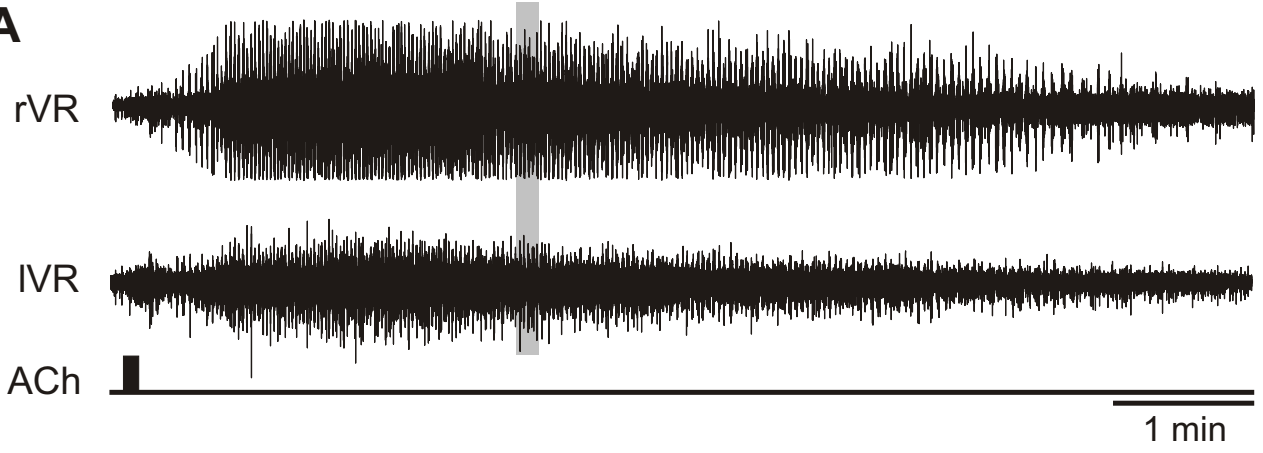

B

rve rithyly

IVR

$200 \mathrm{~ms}$ 
Figure 5

A

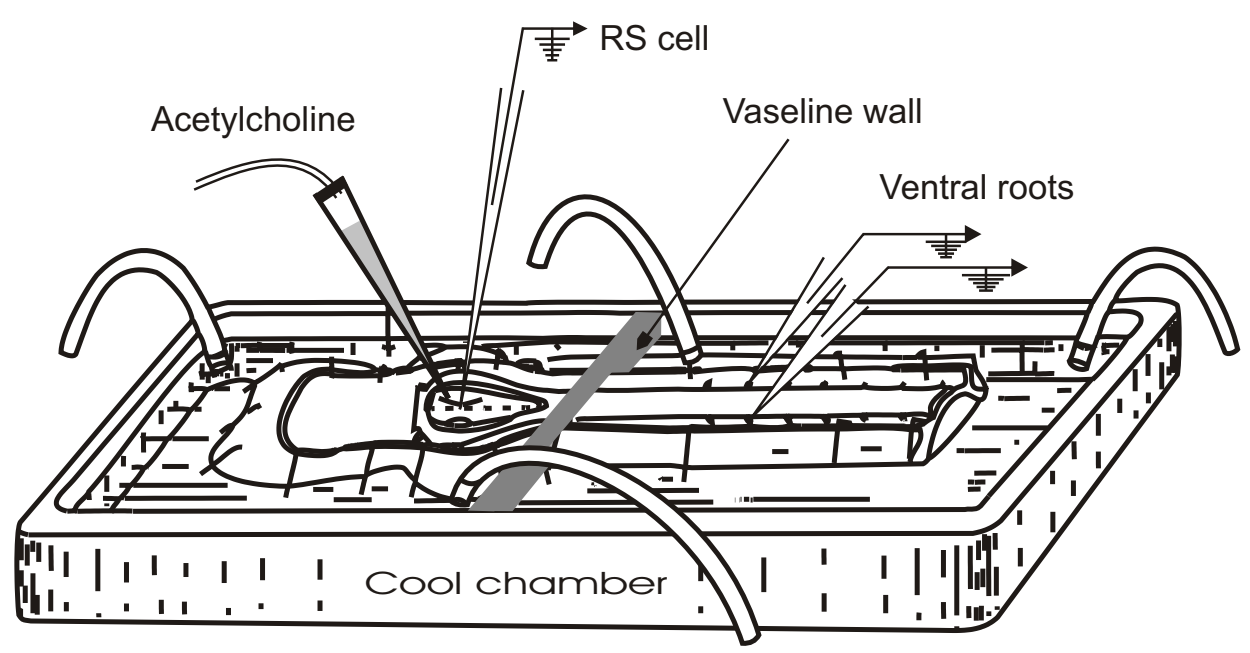

B

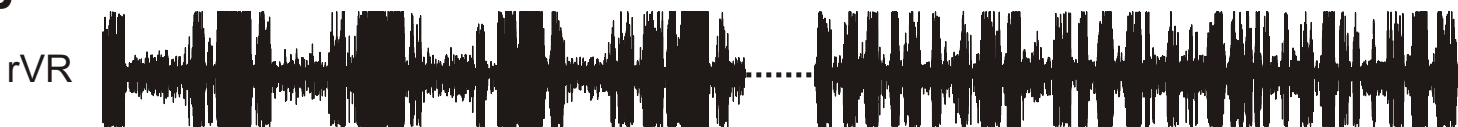

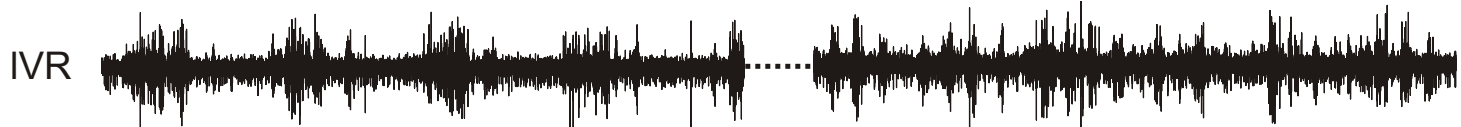
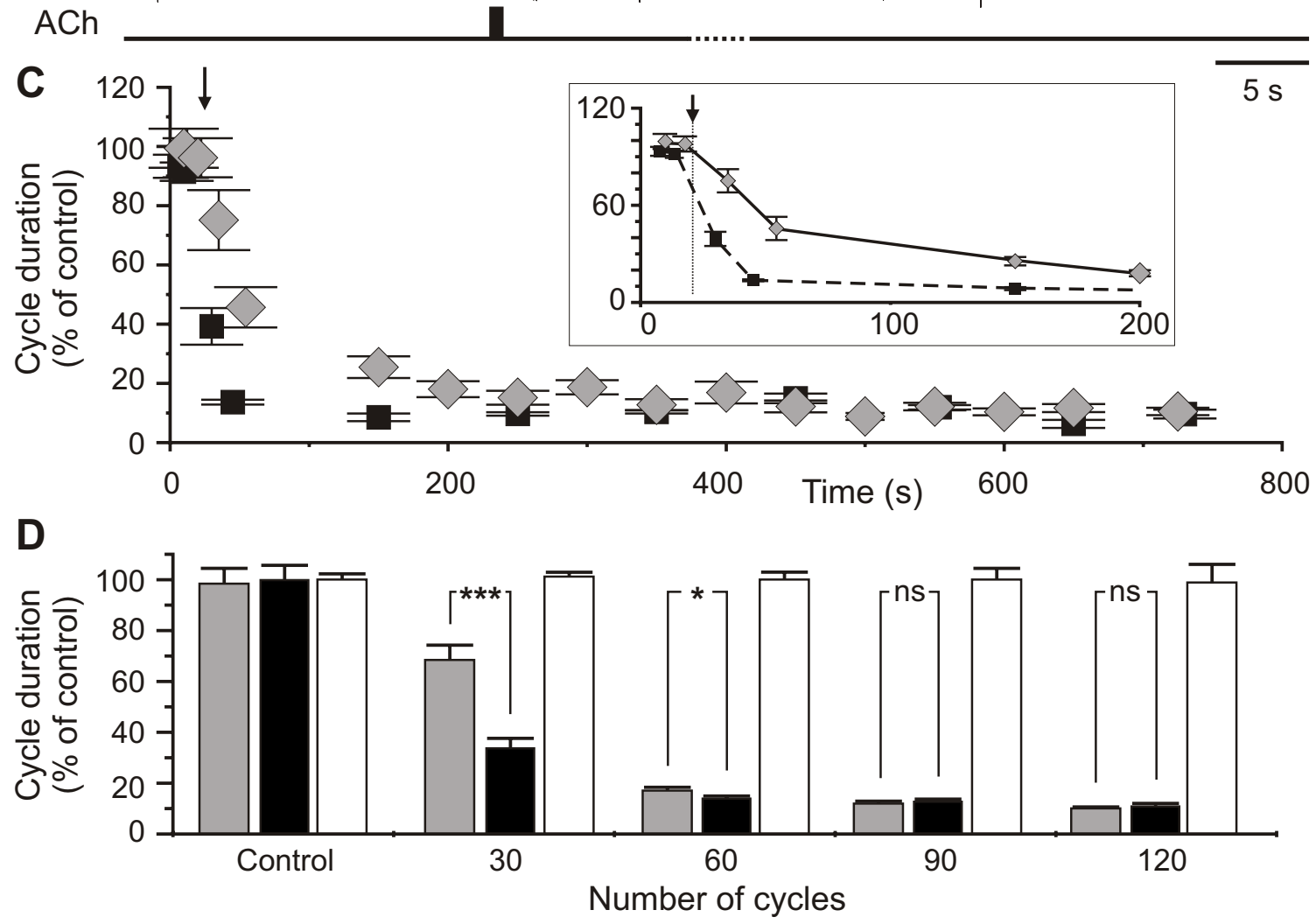


\section{Le Ray et al., 2002 \\ Figure 6}
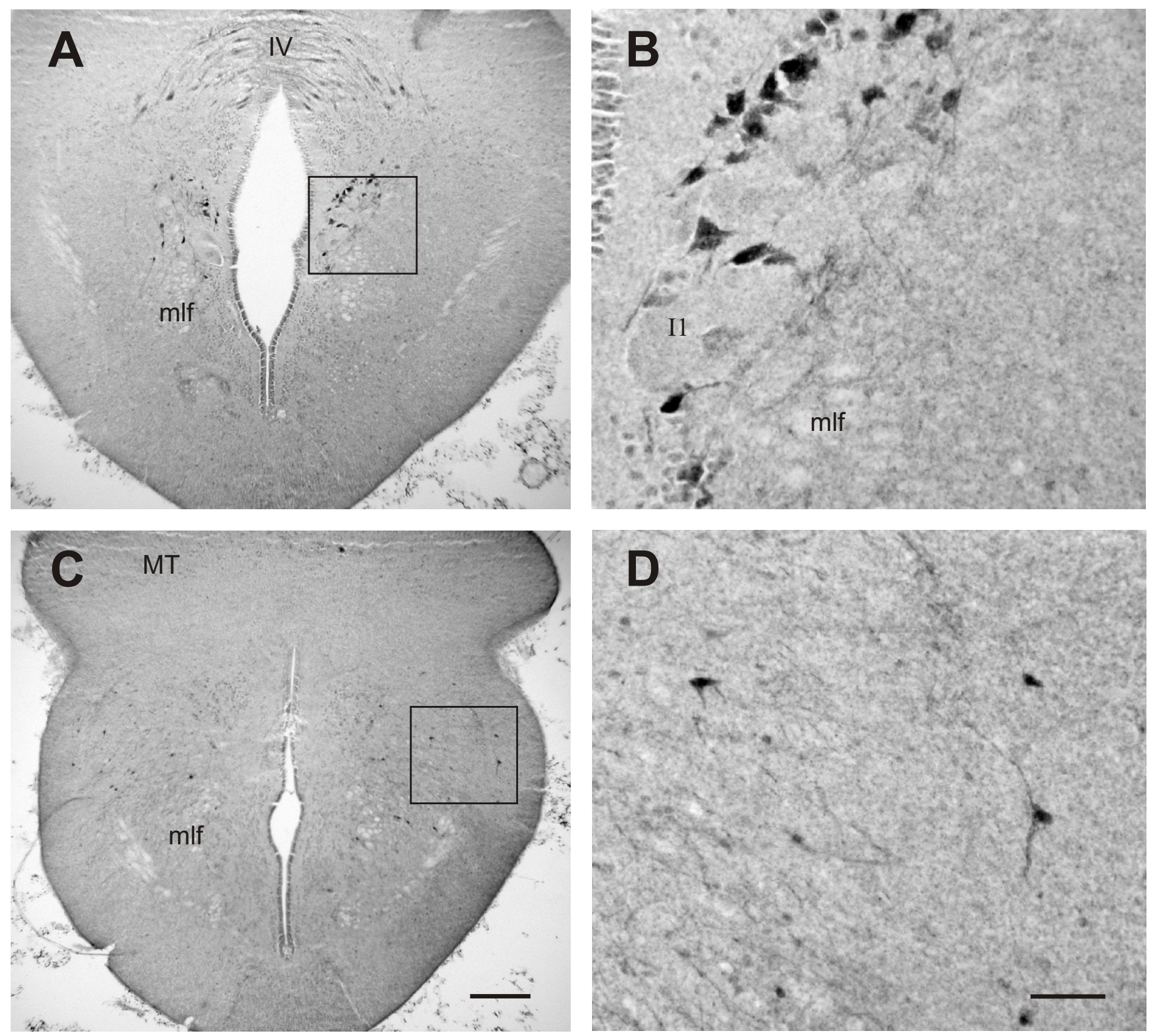


\section{Le Ray et al., 2002}

Figure 7
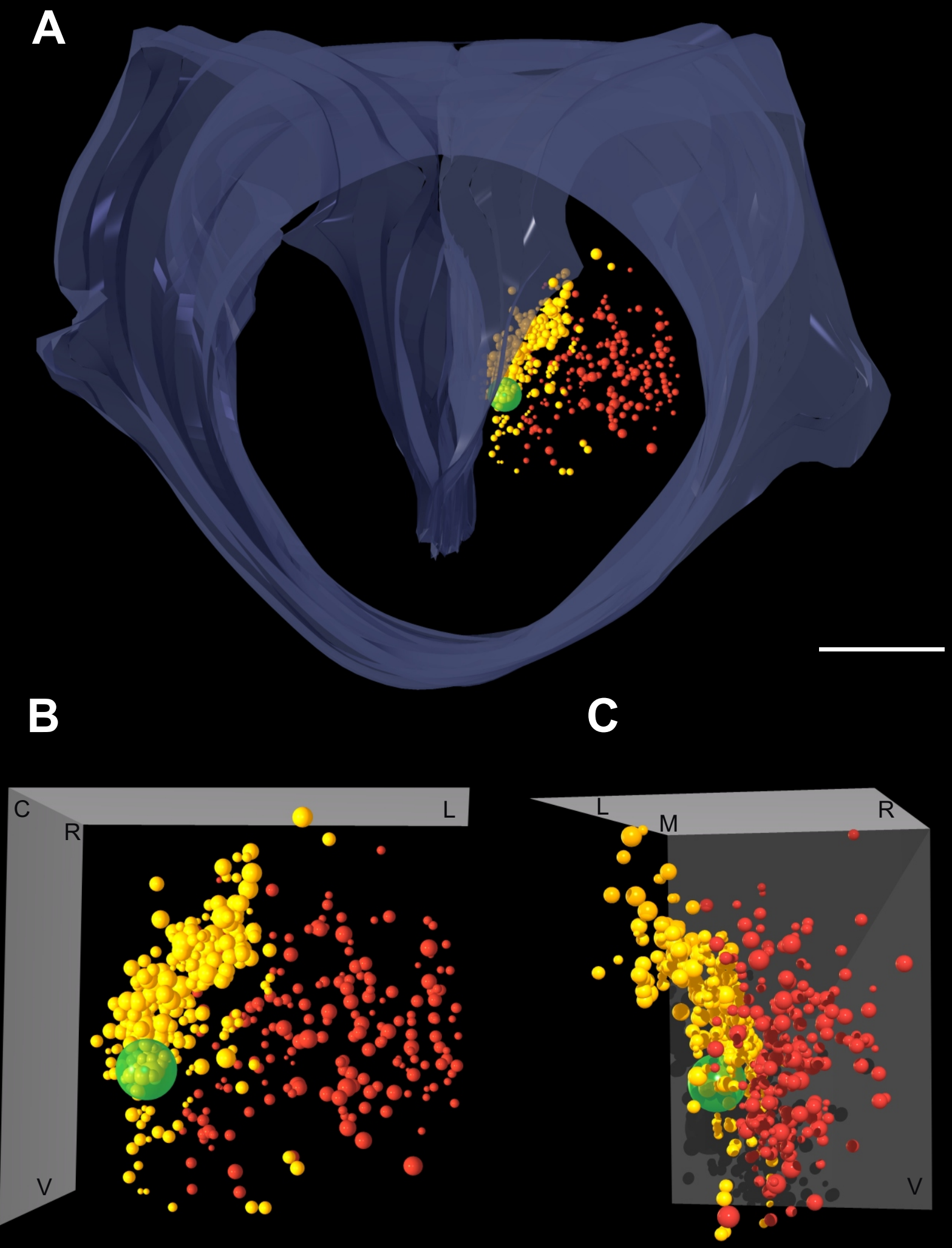
Figure 8
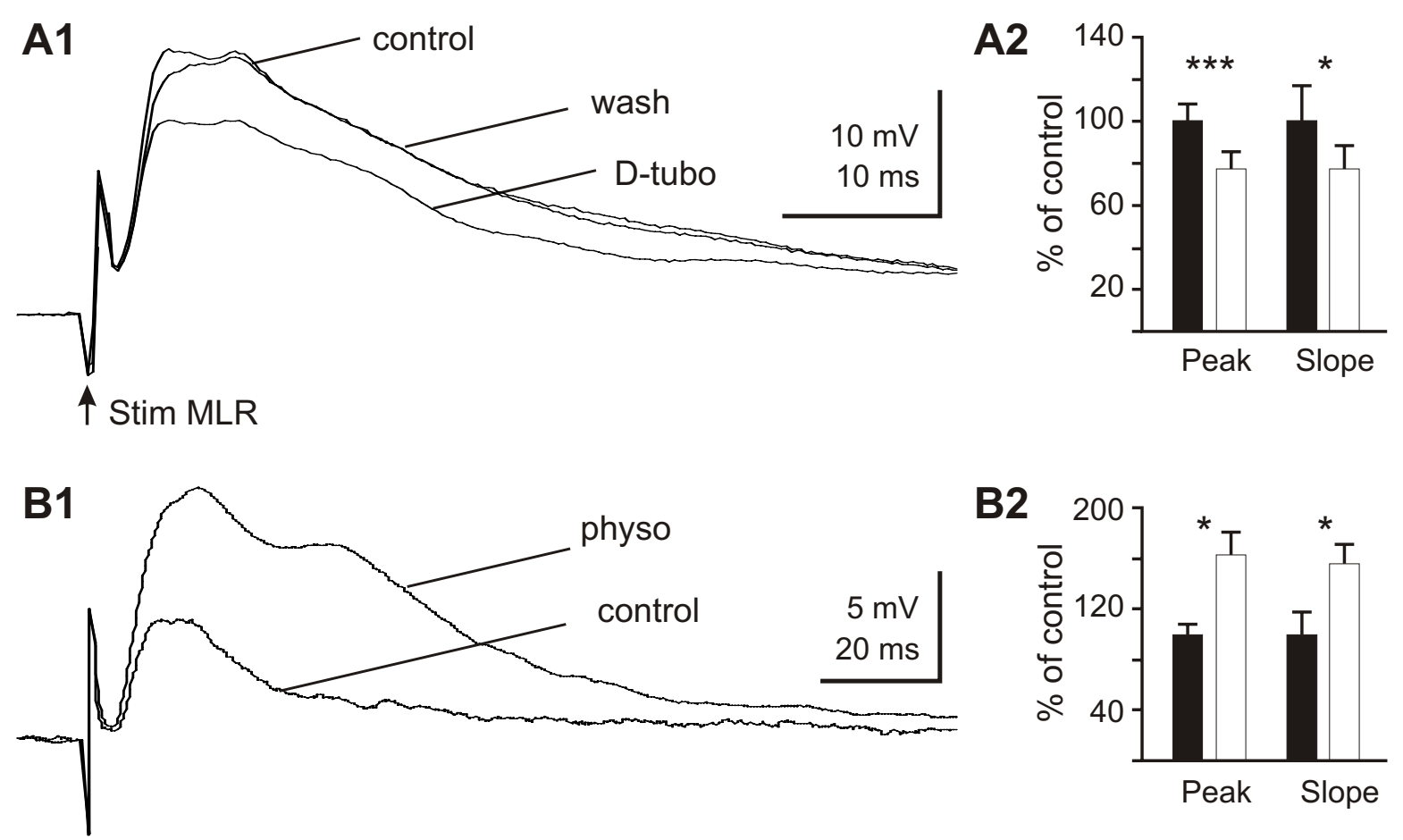

\section{$\uparrow$ Stim MLR}

C1

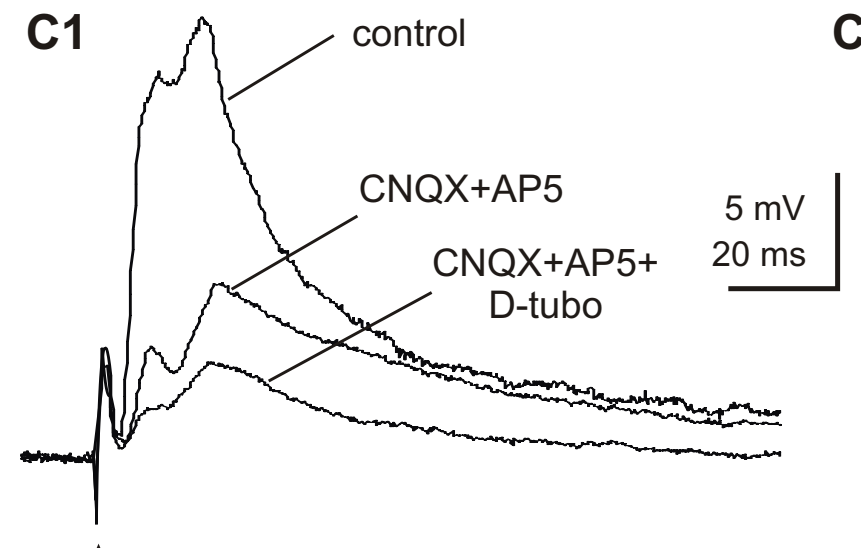

$\uparrow$ Stim MLR
C2 Stim MLR $25 \mathrm{~Hz}$ CNQX+AP5 under High $\mathrm{Ca}^{2+} / \mathrm{Mg}^{2+}$

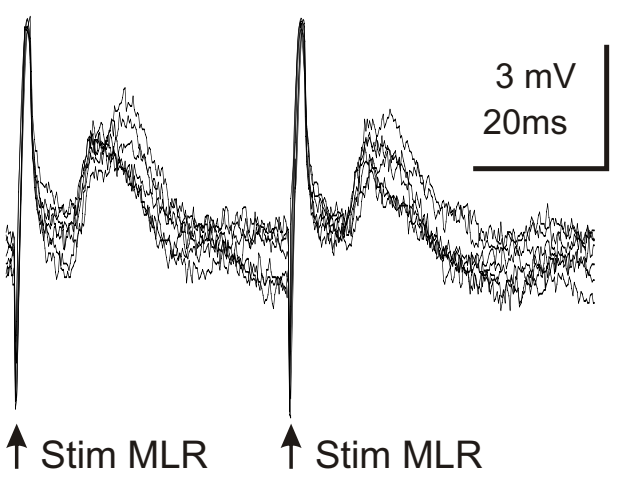




\section{Le Ray et al., 2002}

Figure 9
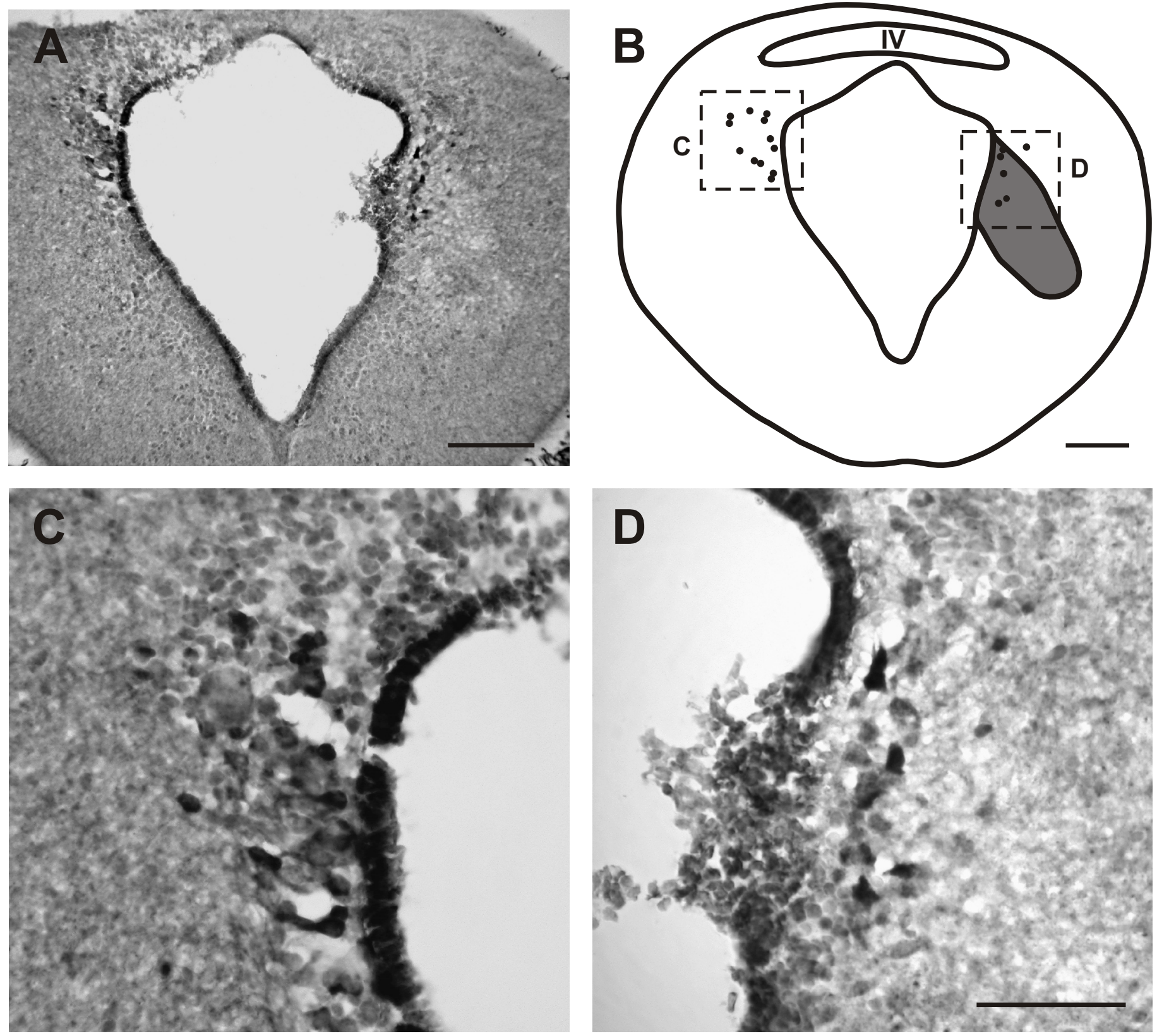
Le Ray et al., 2002

Figure 10
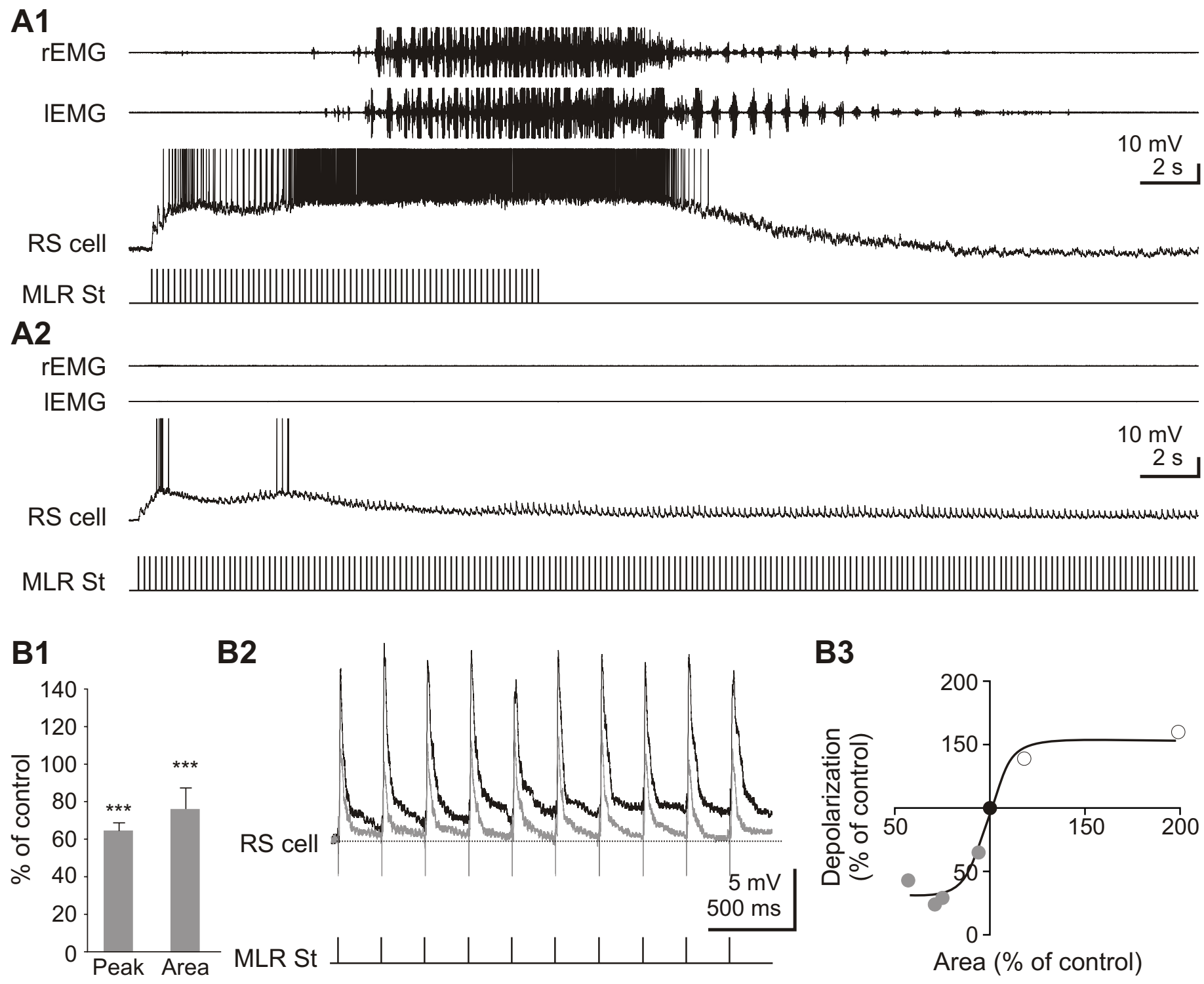

B2

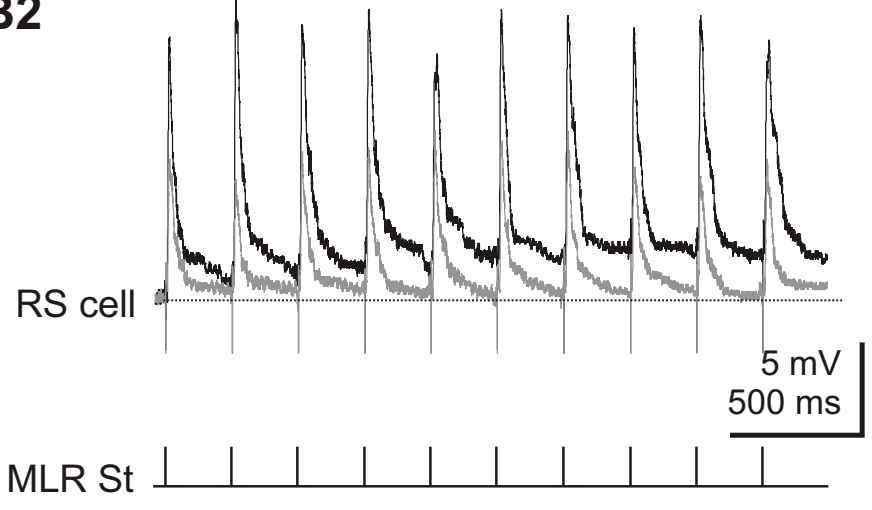

B3

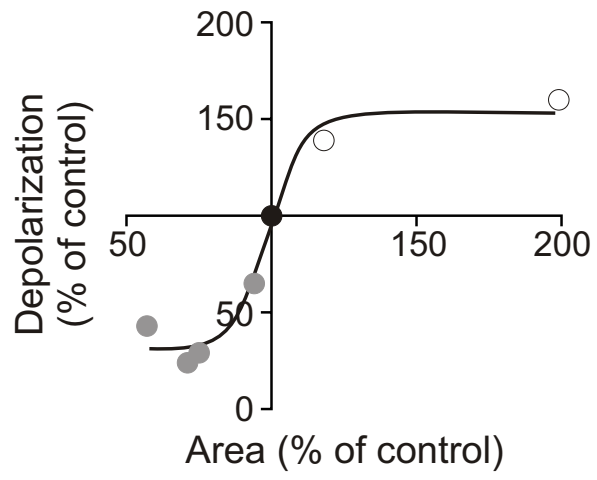

